\title{
HPF1-dependent PARP activation promotes LIG3-XRCC1-mediated backup pathway of Okazaki fragment ligation
}

\author{
Soichiro Kumamoto ${ }^{1}$, Atsuya Nishiyama ${ }^{1,{ }^{*},}$ Yoshie Chiba ${ }^{1}$, Ryota Miyashita ${ }^{1}$, \\ Chieko Konishi ${ }^{1}$, Yoshiaki Azuma ${ }^{2}$ and Makoto Nakanishi ${ }^{\circledR 1}{ }^{*}$
}
${ }^{1}$ Division of Cancer Cell Biology, The Institute of Medical Science, The University of Tokyo, 4-6-1 Shirokanedai, Minato-ku, Tokyo 108-8639, Japan and ${ }^{2}$ Department of Molecular Biosciences, University of Kansas, Lawrence, KS 66045, USA

Received October 21, 2020; Revised March 29, 2021; Editorial Decision March 30, 2021; Accepted April 01, 2021

\begin{abstract}
DNA ligase 1 (LIG1) is known as the major DNA ligase responsible for Okazaki fragment joining. Recent studies have implicated LIG3 complexed with XRCC1 as an alternative player in Okazaki fragment joining in cases where LIG1 is not functional, although the underlying mechanisms are largely unknown. Here, using a cell-free system derived from Xenopus egg extracts, we demonstrated the essential role of PARP1-HPF1 in LIG3-dependent Okazaki fragment joining. We found that Okazaki fragments were eventually ligated even in the absence of LIG1, employing in its place LIG3-XRCC1, which was recruited onto chromatin. Concomitantly, LIG1 deficiency induces ADP-ribosylation of histone H3 in a PARP1-HPF1dependent manner. The depletion of PARP1 or HPF1 resulted in a failure to recruit LIG3 onto chromatin and a subsequent failure in Okazaki fragment joining in LIG1-depleted extracts. Importantly, Okazaki fragments were not ligated at all when LIG1 and XRCC1 were co-depleted. Our results suggest that a unique form of ADP-ribosylation signaling promotes the recruitment of LIG3 on chromatin and its mediation of Okazaki fragment joining as a backup system for LIG1 perturbation.
\end{abstract}

\section{INTRODUCTION}

Lagging strand synthesis is a tightly coordinated stepwise reaction involving multiple proteins, including PCNA, which is an essential component of DNA replication (13 ). When DNA polymerase delta (POL $\delta$ ) reaches the end of a nascent Okazaki fragment, it generates a $5^{\prime}$ flap structure by displacing the $5^{\prime}$ end of the preceding fragment. The displaced $5^{\prime}$ flap is cleaved by nucleases, such as FEN1 or DNA2, and generates a ligatable nick (4-6). Lagging strand synthesis is completed by joining millions of Okazaki fragments through the action of DNA ligases, and a failure of Okazaki fragment joining results in an enormous amount of gap/nick formation on genomic DNA. Therefore, ligation of Okazaki fragments by DNA ligase must be strictly controlled to reliably maintain genome stability.

Vertebrates have three different types of DNA ligases, LIG1, LIG3 and LIG4 (7). LIG1 is the major ligase functioning in DNA replication, and also acts in a fusion of sister chromatids by targeting double-stranded DNA breaks (8). LIG4 plays an essential role in non-homologous endjoining (NHEJ), the pathway for DNA double-strand break repair (DSBR). In budding yeast, the CDC9 gene, a homolog of human LIG1, is essential for viability $(9,10)$. Cdc 9 physically interacts with PCNA via its conserved PCNA interacting peptide (PIP) box motif at the N-terminus and localizes at sites of DNA replication, catalyzing the ligation of Okazaki fragments (11-13). In vertebrates, LIG1 also localizes at DNA replication foci and functions as the main DNA ligase responsible for Okazaki fragment joining $(11,14)$. Unlike yeast, however, LIG1 is not essential for cell survival (15-18), implying the existence of a compensatory pathway other than that of LIG1.

LIG3 is conserved in vertebrates and also in some lower eukaryotes (19). Nuclear LIG3 forms a tight complex with its partner protein X-ray repair cross-complementing protein 1 (XRCC1) and is involved in nucleotide excision repair (NER), single-strand break repair (SSBR), and base excision repair (BER) (7,20-22). It has also been suggested that LIG3 might be responsible for alternative Okazaki fragment ligation in the absence of LIG1. Systematic studies using a chicken B cell line demonstrated that even LIG1/LIG4 double knockout cells are viable (16), suggesting that LIG3 may function in DNA replication in the absence of LIG1.

\footnotetext{
${ }^{*}$ To whom correspondence should be addressed. Tel: +81 35449 5341; Fax: +81 35449 5342; Email: mkt-naka@g.ecc.u-tokyo.ac.jp Correspondence may also be addressed to Atsuya Nishiyama. Tel: +81 35449 5731; Fax: +81 35449 5342; Email: uanishiyama@g.ecc.u-tokyo.ac.jp

(C) The Author(s) 2021. Published by Oxford University Press on behalf of Nucleic Acids Research.

This is an Open Access article distributed under the terms of the Creative Commons Attribution License (http://creativecommons.org/licenses/by/4.0/), which permits unrestricted reuse, distribution, and reproduction in any medium, provided the original work is properly cited.
} 
The question arises as to how LIG3 is specifically localized to DNA replication sites in the absence of LIG1 during S phase progression because the domain structures of LIG1 and LIG3 are very different, especially given that LIG3 lacks a PIP-box. Intriguingly, XRCC1 has been shown to associate and co-localize with PCNA during the S phase $(23,24)$, but other studies have concluded that poly (ADPribose) (PAR) synthesis is important for LIG3-XRCC1 recruitment at chromosomal DNA break sites (25-27).

Mono- and poly-ADP-ribosylation are catalyzed by poly (ADP-ribose) polymerase (PARP) family proteins (28) and degraded by terminal ADP-ribose glycohydrolases (TARG), PAR glycohydrolase (PARG), and ADP-ribose hydrolase (ARH) family (29-31). Among the PARP family, PARP1/2 plays a critical role in the SSBR, and DSBR, the regulation of the stability of DNA replication forks, and maintenance of chromatin structures $(32,33)$. Upon DNA damage, PARP1 rapidly recognizes and binds to a nicked or a gapped single-stranded DNA break via its Nterminal zinc finger domains (34). DNA binding of PARP1 allosterically activates it and promotes its autoPARylation (35), which acts as a platform for tethering SSBR machinery (33). Various PARP1-interacting regulatory factors also play an important role in the regulation of PARP1 activity (33). In response to DNA damage, histone PARylation factor 1 (HPF1) directly binds to the catalytic domain of PARP1/2 via its C-terminal domain (36-38). After the interaction, HPF 1 and PARP1/ 2 jointly form an active site, leading to the enzymatic activation of PARP1/2 (38). Notably, PARP1 in a complex with HPF1 specifically promotes ADP-ribosylation at Ser residues of PARP1, histone proteins, and other chromatin-associated factors $(37,39,40)$. The Ser-ADPr is a major and reversible posttranslational modification in cells in response to DNA damage, and ARH3 is the main enzyme for the reversal of the serine-linked ADP-ribosylation (29). Whether PARP1HPF1-dependent ADP-ribosylation is involved in different types of DNA repair or DNA replication is presently unclear.

Here, using cell-free Xenopus egg extracts, we have shown how the LIG3-XRCC1 complex functions as a backup DNA ligase in the absence of LIG1. Defective Okazaki fragment ligation results in the accumulation of nicked DNA on replicating chromosomes and subsequently induces ADPribosylation of chromatin proteins, including histone $\mathrm{H} 3$. ADP-ribosylation upon LIG1 inactivation occurs in a manner dependent on both PARP1 and HPF1. We also demonstrate that inhibition of PARP1 and HPF1 compromises alternative Okazaki fragment ligation by LIG3-XRCC1.

\section{MATERIALS AND METHODS}

Each experiment was performed at least twice. All oligonucleotide sequences are listed in Supplementary Table S1.

\section{Xenopus interphase egg extracts and purification of chro- matin}

Xenopus laevis was purchased from Kato-S Kagaku and handled according to the animal care regulations at the University of Tokyo. Interphase egg extracts were prepared as described previously (41). Unfertilized Xenopus eggs were dejellied in $2.5 \%$ thioglycolic acid- $\mathrm{NaOH}(\mathrm{pH} 8.2)$, and were washed three times in $0.2 \times$ MMR buffer [ $5 \mathrm{mM}$ HEPES$\mathrm{KOH}$ (pH 7.6), 0.1M NaCl, $2 \mathrm{mM} \mathrm{KCl,} 0.1 \mathrm{mM}$ EDTA, $1 \mathrm{mM} \mathrm{MgCl} 2,2 \mathrm{mM} \mathrm{CaCl}_{2}$ ]. After activation in $1 \times \mathrm{MMR}$ supplemented with $0.3 \mu \mathrm{g} / \mathrm{ml}$ calcium ionophore, eggs were washed four times with EB buffer (10 mM HEPES-KOH pH 7.7, $100 \mathrm{mM} \mathrm{KCl}, 0.1 \mathrm{mM} \mathrm{CaCl}_{2}, 1 \mathrm{mM} \mathrm{MgCl}_{2}, 50$ $\mathrm{mM}$ sucrose). Packed eggs were crushed by centrifugation (BECKMAN, Avanti J-E, JS13.1 swinging rotor) for 20 min at $18973 \times$ g. Egg extracts were supplemented with $50 \mu \mathrm{g} / \mathrm{ml}$ cycloheximide, $20 \mu \mathrm{g} / \mathrm{ml}$ cytochalasin $\mathrm{B}, 1 \mathrm{mM}$ DTT, $2 \mu \mathrm{g} / \mathrm{ml}$ aprotinin and $50 \mu \mathrm{g} / \mathrm{ml}$ leupeptin and clarified for $20 \mathrm{~min}$ at $48400 \times \mathrm{g}$ (Hitachi, CP100NX, P55ST2 swinging rotor). The cytoplasmic extracts were aliquoted, frozen with liquid nitrogen, and stored at $-80^{\circ} \mathrm{C}$. Chromatin purification after incubation in egg extracts was performed as previously described with modifications (42). Sperm nuclei were incubated in egg extracts supplemented with an ATP regeneration system $(20 \mathrm{mM}$ phosphocreatine, $4 \mathrm{mM}$ ATP, $5 \mu \mathrm{g} / \mathrm{ml}$ creatine phosphokinase) at 3000-4000 nuclei/ $\mu 1$ at $22^{\circ} \mathrm{C}$. Aliquots $(15 \mu \mathrm{l})$ were diluted with 150 $200 \mu$ l chromatin purification buffer (CPB; $50 \mathrm{mM} \mathrm{KCl}, 5$ $\mathrm{mM} \mathrm{MgCl} 2,20 \mathrm{mM}$ HEPES-KOH, pH 7.7) containing $0.1 \%$ NP- $40,2 \%$ sucrose and $2 \mathrm{mM}$ NEM. After incubating on ice for $5 \mathrm{~min}$, extracts were layered over $1.5 \mathrm{ml}$ of CPB containing $30 \%$ sucrose and centrifuged at $15000 \times \mathrm{g}$ for $10 \mathrm{~min}$ at $4^{\circ} \mathrm{C}$. Chromatin pellets were resuspended in $1 \times$ SDS sample buffer, heated for $5 \mathrm{~min}$, and analyzed by SDSPAGE. To inhibit DNA replication, aphidicolin was added to egg extracts at a final concentration of $30 \mu \mathrm{M}$.

\section{Antibodies and immunodepletions}

Rabbit polyclonal Xenopus LIG1 antibodies were raised against a bacterially expressed recombinant protein encoding a His10-tagged 420-amino -acid fragment from the Nterminus of Xenopus LIG1. FEN1 antibodies were raised against the recombinant His10-tagged full-length protein. LIG3 antibodies were raised against a bacterially expressed recombinant protein encoding a C-terminal fragment containing amino acids $638-903$ of xLIG3. XRCC1 antibodies were raised against an $\mathrm{N}$-terminus fragment of Xenopus XRCC1 encoding amino acids $1-313$, which was tagged on the $\mathrm{N}$ terminus with His10. xHPF1 and xARH3 antibodies were raised against a bacterially expressed fulllength protein, which was tagged on the $\mathrm{N}$ terminus with His10. PARP1 antibodies used for immunodepletion were raised against a fragment containing amino acids 500-650 of XPARP1. PARG antibodies used for immunoblotting were raised against a bacterially expressed $\mathrm{N}$-terminus fragment containing 1-385 of xPARG, which was tagged on the $\mathrm{N}$ terminus with His10. Antibodies against the protein fragments were raised in rabbits by immunization (Hokudo Co.,Ltd). Histone $\mathrm{H} 3$ antibodies were obtained from $\mathrm{Ab}-$ cam (ab1791). Antibodies against PCNA were obtained from SantaCruz (PC10). Pan-ADP-ribose detecting reagent was obtained from Millipore (MABE1016). Antibodies against RPA34 were a generous gift of M. Mechali (Institute of Human Genetics, CNRS). For xPARP1 or xHPF1 depletion, $250 \mu \mathrm{l}$ of antiserum were coupled to $50 \mu \mathrm{l}$ of recom- 
binant protein A-sepharose (rPAS, GE Healthcare). Antibody beads were washed three times in PBS and treated with $5 \mu \mathrm{l}$ fresh rPAS. Beads were washed twice in CPB, split into three portions, and $100 \mu \mathrm{l}$ extracts were depleted in three rounds at $4^{\circ} \mathrm{C}$, each for $1 \mathrm{~h}$. For xLIG1 and xXRCC1 depletion, $170 \mu \mathrm{l}$ of antiserum were coupled to $35 \mu \mathrm{l}$ of rPAS. Antibody beads were washed three times in PBS and treated with $4 \mu \mathrm{l}$ fresh rPAS. Beads were washed twice in CPB, split into two portions, and $100 \mu \mathrm{l}$ extracts were depleted in two rounds at $4^{\circ} \mathrm{C}$, each for $1 \mathrm{~h}$. For add-back experiments, recombinant xLIG1 was added to xLIG1-depleted extracts at $81 \mathrm{nM}$, and recombinant xLIG3 or xLIG3-xXRCC1 complex were added to xLIG3-xXRCC1-depleted extracts at $28 \mathrm{nM}$.

\section{Measurement of DNA replication efficiency in Xenopus egg extracts}

$\alpha{ }^{3}{ }^{32} \mathrm{P}$ dCTP $(3000 \mathrm{Ci} / \mathrm{mmol}$ ) was added to an interphase extract containing sperm nuclei and incubated at $22^{\circ} \mathrm{C}$. At each time point, extracts were diluted in reaction stop solution (1\% SDS, $40 \mathrm{mM}$ EDTA) supplemented with Proteinase K (NACALAI TESQUE, Inc.), followed by overnight incubation at $37^{\circ} \mathrm{C}$. The reaction solution was spotted on a glass filter and then precipitated with a $5 \%$ TCA solution containing 2\% pyrophosphate. Filters were washed twice with 5\% TCA, and then twice with ethanol. After filters were dried, the incorporation of radioactivity was counted in scintillation liquid. Radiolabeled dCTP in chromosomal DNA was also monitored by autoradiography following alkaline agarose gel electrophoresis.

\section{Immunoprecipitation from Xenopus egg extracts}

$5 \mu \mathrm{l}$ of antiserum were diluted with $250 \mu \mathrm{l}$ of PBS containing $0.05 \%$ NP-40 and coupled to $10 \mu 1$ of Protein AAgarose beads (Roche) by rotating at $4{ }^{\circ} \mathrm{C}$ overnight. Egg extracts were diluted fivefold with CPB buffer and cleared by centrifugation for $10 \mathrm{~min}$ at $14000 \times$ g. $50-100 \mu \mathrm{l}$ of the supernatant was incubated with antibody beads for $1-$ $2 \mathrm{~h}$ at $4^{\circ} \mathrm{C}$. Beads were then washed three times with CPB buffer containing $0.1 \%$ Triton X-100. The bead-bound proteins were eluted with SDS sample buffer and analyzed by immunoblotting. In this case, Protein A-HRP was used as the secondary antibody.

\section{Histone $\mathrm{H} 3$ precipitation from chromatin}

Immunoprecipitation of histone $\mathrm{H} 3$ from the chromatin fraction was performed as described previously (43). Briefly, mock- or LIG1-depleted extracts containing sperm nuclei were diluted fivefold with CPB supplemented with $0.1 \%$ NP-40, $2 \mathrm{mM}$ NEM and $2 \mathrm{mM}$ tannic acid. After incubating on ice for $5 \mathrm{~min}$, extracts were layered over a sucrose step gradient composed of $500 \mu \mathrm{l}$ CPB buffer containing $30 \%$ sucrose and $10 \mu 12 \mathrm{M}$ sucrose. Chromatin fractions were resuspended in a $50 \mu 1$ sucrose cushion, and then supplemented with $50 \mu \mathrm{l}$ of $2 \times$ nuclease solution [40 $\mathrm{mM}$ K-HEPES (pH 7.5), $200 \mathrm{mM} \mathrm{KCl,} 5 \mathrm{mM} \mathrm{MgCl} 2], 0.1 \%$ Triton-100, $0.4 \mathrm{mM} \mathrm{CaCl}_{2}$, MNase (4 U/ml)] and incubated at $22^{\circ} \mathrm{C}$ for $20 \mathrm{~min}$. The reaction was stopped by the addition of EDTA to $10 \mathrm{mM}$ (final concentration), and the supernatant was obtained by centrifugation at $15000 \mathrm{rpm}$ for $10 \mathrm{~min}$ and used as a chromatin-solubilized sample. SDS was added to the supernatant to a final concentration of $1 \%$, and diluted with tenfold Lysis buffer ( $1 \%$ Triton X-100, 1 mM EDTA, $150 \mathrm{mM} \mathrm{NaCl}, 15 \mathrm{mM}$ Tris-HCl, pH 8.0). The chromatin lysates were incubated for $2 \mathrm{~h}$ at $4{ }^{\circ} \mathrm{C}$ with $2 \mu \mathrm{g}$ of anti-histone $\mathrm{H} 3$ antibody conjugated to $10 \mu \mathrm{l}$ of Protein A-agarose beads. After the beads were washed with lysis buffer, the bound protein was eluted with SDS sample buffer and analyzed by immunoblotting.

\section{Protein expression and purification}

His10-xLIG1 (1-420), His10-xLIG3 (683-903), His10xXRCC1 (1-313), His10-xPARP1 (600-750), His10xPARG (1-385), His10-xARH3 (full-length) and His10xHPF1 (full-length) were expressed and purified from bacteria cells. Escherichia coli BL21-CodonPlus-RIL strain (Agilent) was transformed with a pET19b vector inserted with a DNA fragment encoding a target protein sequence. Cells were cultured in $\mathrm{LB}$ medium until the $\mathrm{OD}_{600}$ reached 0.6. The culture was supplemented with $0.25 \mathrm{mM}$ IPTG for $16 \mathrm{~h}$ at $20^{\circ} \mathrm{C}$. Cells were harvested and washed twice with ice-cold PBS, and then lysed in $10 \mathrm{ml}$ lysis buffer (50 $\mathrm{mM} \mathrm{NaH} \mathrm{PO}_{4}, 300 \mathrm{mM} \mathrm{NaCl}, 10 \mathrm{mM}$ imidazole, $\mathrm{pH}$ 8.0) supplemented with $1 \% \mathrm{NP}-40,2 \mu \mathrm{g} / \mathrm{ml}$ aprotinin, $5 \mu \mathrm{g} / \mathrm{ml}$ leupeptin, $100 \mu \mathrm{g} / \mathrm{ml}$ PMSF, $20 \mu \mathrm{g} / \mathrm{ml}$ trypsin inhibitor by sonication and cleared by centrifugation at $5000 \mathrm{rpm}$ for 10 min. Cleared lysates were incubated with Ni-NTA agarose (QIAGEN) at $4^{\circ} \mathrm{C}$ for $2 \mathrm{~h}$. The agarose beads were washed with lysis buffer containing $20 \mathrm{mM}$ imidazole. Bead-bound proteins were eluted with lysis buffer containing $500 \mathrm{mM}$ imidazole. His10-HPF1 was further applied to a PD-10 desalting column (GE Healthcare BioSciences) equilibrated with EB containing $1 \mathrm{mM}$ DTT.

xLIG1-3 $\times$ Flag was expressed and purified from insect cells. Briefly, Xenopus LIG1 with a C-terminal Flag x 3 tag was cloned into pVL1392 using primers No. 3 and No.4. F8A/F9A and K721A mutations in pKS104-xLIG1 constructs were introduced using a KOD-Plus Mutagenesis kit (Toyobo). Baculoviruses were produced using a BD BaculoGold Transfection kit and a BestBac Transfection kit (BD Biosciences), following the manufacturer's protocol. Proteins were expressed in $\mathrm{Sf} 9$ insect cells by infection with viruses expressing wild type xLIG1-3× Flag, or its mutant for $72 \mathrm{~h}$. Sf9 cells were lysed by resuspension in lysis buffer (20 mM Tris- $\mathrm{HCl}, \mathrm{pH} 8.0,100 \mathrm{mM} \mathrm{KCl}, 5 \mathrm{mM} \mathrm{MgCl} 2,10 \%$ glycerol, $1 \%$ Nonidet P40 (NP-40), $1 \mathrm{mM} \mathrm{DTT,} 10 \mu \mathrm{g} / \mathrm{ml} \mathrm{le}-$ upeptin and $10 \mu \mathrm{g} / \mathrm{ml}$ aprotinin). A soluble fraction was obtained after centrifugation of the lysate at $15000 \times \mathrm{g}$ for 15 min at $4{ }^{\circ} \mathrm{C}$. The fraction was incubated for $4 \mathrm{~h}$ at $4{ }^{\circ} \mathrm{C}$ with $250 \mu 1$ of anti-FLAG M2 affinity resin (Sigma-Aldrich) equilibrated with lysis buffer. The beads were collected and washed with $10 \mathrm{ml}$ wash buffer $(20 \mathrm{mM}$ Tris- $\mathrm{HCl}$, pH 8.0, $100 \mathrm{mM} \mathrm{KCl}, 5 \mathrm{mM} \mathrm{MgCl} 2,10 \%$ glycerol, $0.1 \%$ NP-40, 1 $\mathrm{mM}$ DTT) and then with $5 \mathrm{ml} \mathrm{EB}(20 \mathrm{mM}$ HEPES-KOH, $\mathrm{pH} 7.5,100 \mathrm{mM} \mathrm{KCl}, 5 \mathrm{mM} \mathrm{MgCl}_{2}$ ) containing $1 \mathrm{mM}$ DTT. The recombinant xLIG1 was eluted twice in $250 \mu 1 \mathrm{~EB}$ containing $1 \mathrm{mM}$ DTT and $250 \mu \mathrm{g} / \mathrm{ml} 3 \times$ Flag peptide (Sigma- 
Aldrich). Eluates were pooled and concentrated using a Vivaspin 500 (GE Healthcare Biosciences, VS0121). 3× FlagxLIG3/xXRCC1-myc was purified from insect cells as described above. pVL1392-3 × Flag-xLIG3 and pVL1392$\mathrm{xXRCC1-myc}$ were co-transfected and expressed in Sf9 insect cells for $72 \mathrm{~h}$.

In vitro translation was performed using a TNT SP6 Quick Coupled Transcription/Translation System (Promega, L2080). $40 \mu 1$ of rabbit reticulocyte lysates supplemented with methionine were incubated with $1 \mu \mathrm{g}$ of pKS103-xLIG1, pKS104-xLIG1, pKS103-xLIG3, or pKS103-xXRCC1 for $90 \mathrm{~min}$ at $30^{\circ} \mathrm{C}$. Lysates expressing recombinant protein were frozen with liquid nitrogen and stored at $-80^{\circ} \mathrm{C}$.

\section{Okazaki fragment analysis}

Genomic DNA was isolated from egg extracts using a Wizard Genomic DNA purification kit (Promega, A1120). $0.5 \mu \mathrm{g}$ of DNA were used in labeling reactions in endlabel buffer (0.5 mM dNTPs, $50 \mathrm{mM}$ Tris- $\mathrm{HCl}$ pH 8.0, 10 $\mathrm{mM} \mathrm{MgCl} 2$ ) and $10 \mathrm{U}$ Klenow (exo-) polymerase (NEB, $\mathrm{M} 0212 \mathrm{~S}$ ) and $\alpha-{ }^{32} \mathrm{P}-\mathrm{dCTP}$ (Perkin Elmer) at $37^{\circ} \mathrm{C}$ for $1 \mathrm{~h}$. The reaction mixture was treated with an equal volume of $2 \times$ alkaline loading buffer (100 mM NaOH, 2 mM EDTA, $2.5 \%$ Ficoll, $0.025 \%$ bromocresol green). Labeled DNA was separated in $1.2 \%$ denaturing agarose gels $(50 \mathrm{mM} \mathrm{NaOH}$, $1 \mathrm{mM}$ EDTA) and run at $50 \mathrm{~V}$ and $30 \mathrm{~mA}$ for $7 \mathrm{~h}$. In order to prevent the loss of small fragments ( $<150 \mathrm{bp})$, the gel was fixed by incubation with $7 \%$ TCA for 30 min on a shaker, dried and then exposed to phosphor screens or X-ray film.

\section{RESULTS}

LIG1 is a ligase responsible for Okazaki fragment joining in Xenopus egg extracts

We used a cell-free system derived from Xenopus egg extracts to delineate mechanisms of Okazaki fragment joining in vertebrates. We first examined whether LIG1 is required for ligation of Okazaki fragments in egg extracts. We cloned the full-length cDNA of Xenopus LIG1 (xLIG1), encoding a 1,070 amino acid protein with significant homology to human LIG1 (hLIG1) (88\% amino acid similarity) (Supplementary Figure S1A). A fragment of the xLIG1 encoding amino acids $1-420$ was purified as a 10 tandem Histag fused protein and used for specific antigen preparation. The antiserum specifically recognized an approximately 160 $\mathrm{kDa}$ band in extracts as well as a full-length xLIG1 recombinant protein generated by in vitro translation with $3 \times$ Flag-tag $(3 \times$ Flag-xLIG1 or xLIG1-3× Flag) (Supplementary Figure S1B). Note that LIG1 is present as phosphorylated and non-phosphorylated forms in egg extracts, as shown by the treatment with calf intestinal alkaline phosphatase (CIP) of xLIG1 immunoprecipitates (Supplementary Figure S1C).

Consistent with previous reports using budding yeast and mammalian cells, our antibodies co-immunoprecipitated xLIG1 with xPCNA from extracts (Figure 1A). A pulldown experiment using a recombinant wild-type xLIG1$3 \times$ Flag showed a tight interaction between xLIG1 and xPCNA whereas that using its mutant within a PIP-box did not (Figure 1B and C). In addition, we found that xLIG1 as well as xPCNA and XFEN1 accumulated on chromatin during $\mathrm{S}$ phase. This binding was completely abolished by the addition of a DNA polymerase inhibitor, aphidicolin (APH) (Figure 1D and Supplementary Figure S1D). These results indicate that xLIG1 accumulates on S-phase chromatin in a DNA replication-dependent manner.

To test whether LIG1 is required for Okazaki fragment joining in Xenopus egg extracts, we immunodepleted xLIG1 from egg extracts and examined the accumulation of small DNA fragments during $\mathrm{S}$ phase, which was initiated by the addition of sperm DNA. More than $99 \%$ of xLIG1 was depleted without a significant effect on gross DNA replication of sperm chromatin (Figure 1E and Supplementary Figure S1E). However, denaturing agarose gel analysis of DNA replication products revealed the accumulation of short DNA fragments in xLIG1-depleted extracts, but not in mock-depleted extracts, presumably a result of a failure of Okazaki fragment ligation (Figure 1F). We then labeled unligated Okazaki fragments using DNA polymerase and $\alpha-{ }^{32} \mathrm{P}-\mathrm{dCTP}$. In mock-depleted extracts, nicked DNA was almost undetectable. In contrast, xLIG1 depletion resulted in a transient but marked accumulation of short nascent DNA fragments (Figure 1G). The defective joining of Okazaki fragments was rescued by the addition of wildtype xLIG1 recombinant protein (Figure 1G). In contrast, a mutant xLIG1 lacking enzymatic activity (44-46) failed to join Okazaki fragments (Figure 1G, Supplementary Figure S6A), although the chromatin binding of the mutant was comparable to that of the wild-type (Supplementary Figure S1F and G). Reintroduction of recombinant mutant xLIG1 (R794L and R924W), a point mutant that was identified in an immunodeficient patient $(46,47)$, also showed a defect in Okazaki fragment joining similar to that of the inactive mutant, and retained chromatin binding activity (Supplementary Figure S1H-L, Supplementary Figure S6A). A previous study in yeast showed that the completion of Okazaki fragment joining triggers ELG1/ATAD5-RFC-dependent PCNA unloading from chromatin (48). Consistent with this, immunodepletion of xLIG1 resulted in increased chromatin binding of XPCNA, and XFEN1, but the accumulation was diminished with the progression of S phase (Supplementary Figure S1M and N). These results confirm the importance of the DNA ligase activity of LIG1 in Okazaki fragment joining in Xenopus egg extracts.

\section{A LIG3-XRCC1 complex acts to compensate for Okazaki fragment ligation for LIG1 function}

Notably, the accumulation of nicked DNA in LIG1depleted extracts was diminished with the progression of $\mathrm{S}$ phase (Figure $1 \mathrm{G}$ ), suggesting the existence of a compensatory pathway other than that of LIG1 for Okazaki fragment joining in egg extracts. Previously, the viability of cells lacking LIG1 was reported to depend on LIG3 function $(16,17)$. Therefore, we examined the possibility that the LIG3-XRCC1 complex acts as part of a compensatory system for the Okazaki fragment joining. A comparison of nucLIG3- $\alpha$ and XRCC1 between humans and Xenopus revealed conserved domain structures with $61-88 \%$ and 70 $78 \%$ homology, respectively (Supplementary Figure S2A). 
A

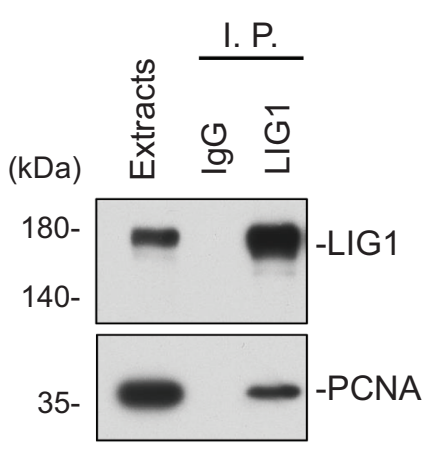

B

Xenopus LIG1

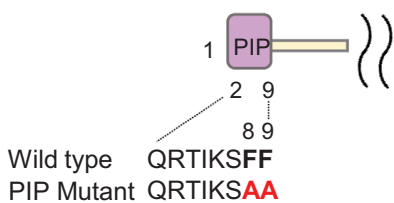

C

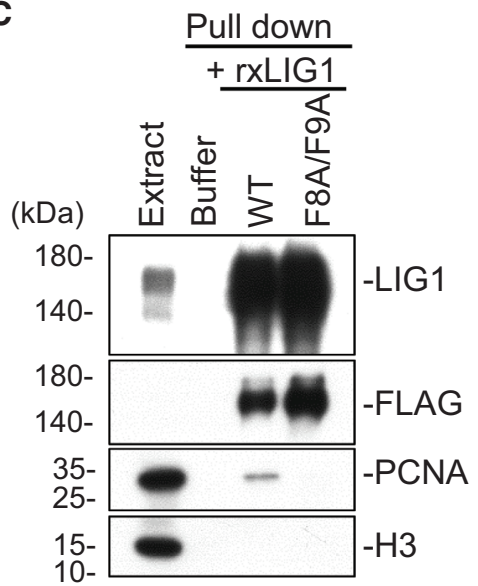

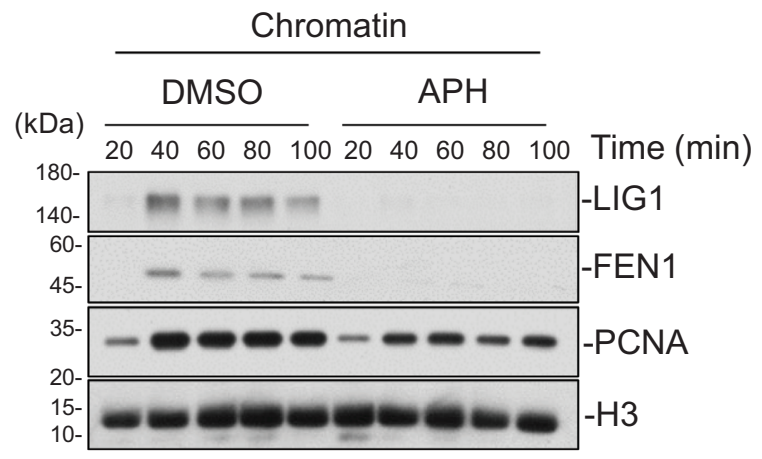

E
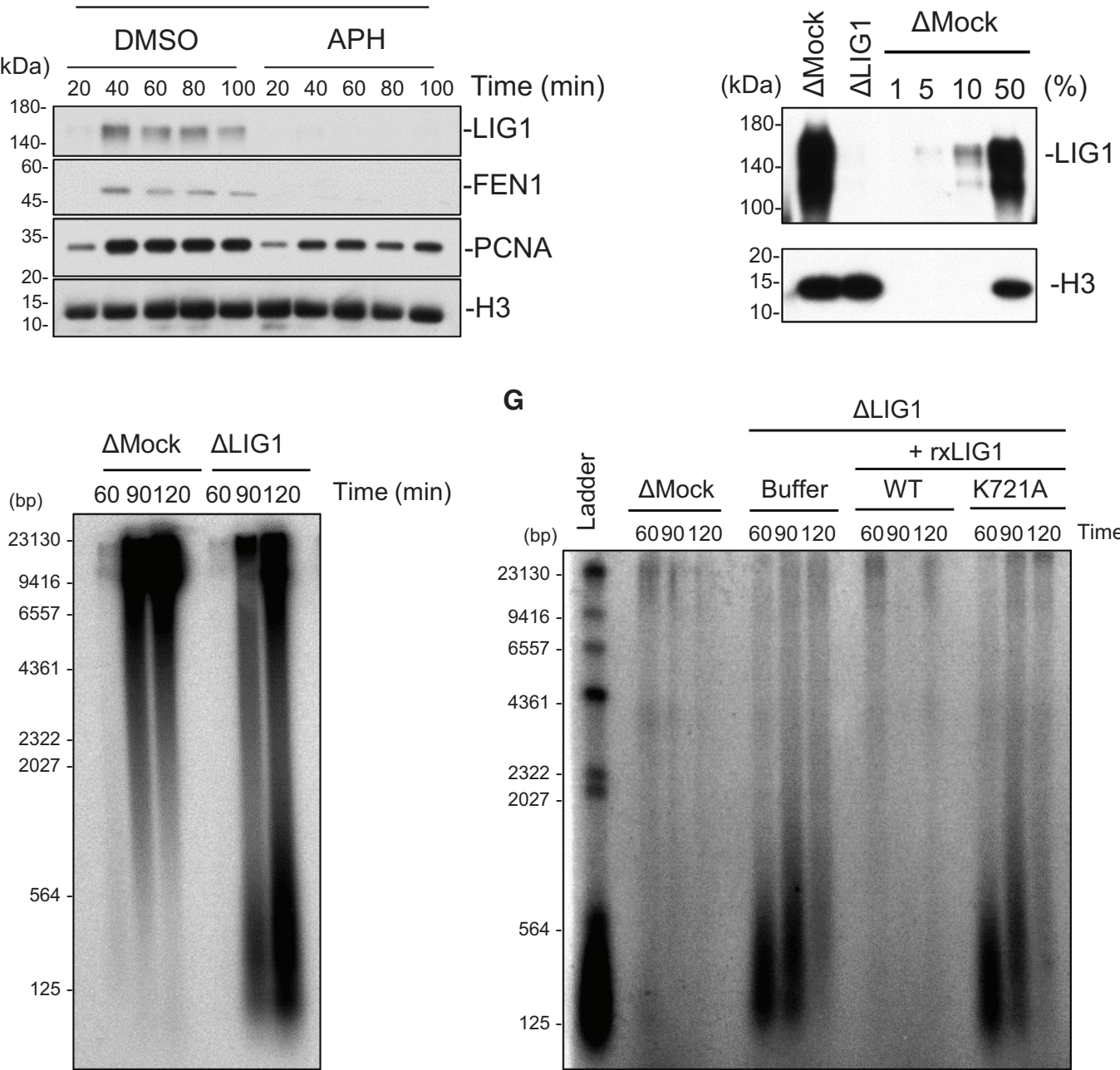

G

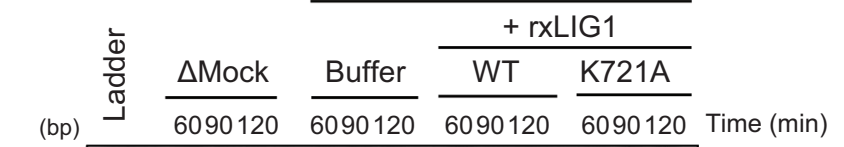

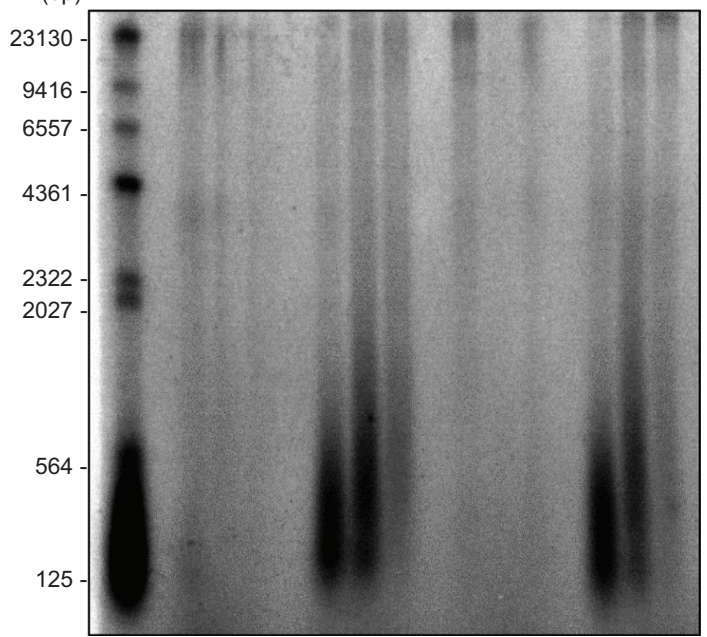

Figure 1. Depletion of LIG1 inhibits Okazaki fragment ligation in Xenopus egg extracts. (A) Control or xLIG1 antibodies were used for immunoprecipitation (I. P.) and immunoprecipitated proteins were analyzed by immunoblotting using the indicated antibodies $(n=2)$. (B) Sequences of the wild-type and the F8A/F9A mutant PIP-box in xLIG1 are shown. (C) Recombinant wild-type xLIG1-3 $\times$ Flag or xLIG1-F8A/F9A-3 $\times$ Flag was added to the egg extracts. Immunoprecipitation using anti-Flag antibodies was performed and resultant immunoprecipitates were analyzed by immunoblotting using the indicated antibodies $(n=2)$. (D) Interphase egg extracts were added with sperm chromatin and incubated in the presence of $30 \mu \mathrm{M}$ aphidicolin or in its absence (DMSO). Chromatin fractions were isolated and analyzed by immunoblotting using the indicated antibodies $(n=2)$. (E) Immunodepletion efficiency of xLIG1 from Xenopus egg extract $(n=3)$. (F) Replication products in mock- or xLIG1-depleted extracts were separated by alkaline agarose gel electrophoresis followed by autoradiography $(n=2)$. (G) xLIG1-depleted extracts were supplemented with wild-type xLIG1-3 $\times$ Flag or xLIG1-K721A-3 $\times$ Flag and chromatin was isolated. Purified genomic DNA from chromatin was labeled using exonuclease-deficient Klenow fragment and $\alpha-{ }^{32} \mathrm{P} d C T P$, and separated in a denaturing agarose gel $(n=2)$. 
To clarify the function of Xenopus LIG3-XRCC1 complex, we raised antibodies against xLIG3 and xXRCC1. These antibodies recognized polypeptides of the expected molecular weight in egg extracts as well as their recombinant proteins expressed in reticulocyte lysates as a control (Supplementary Figure S2B). We showed that xLIG3 and XXRCC1 stably interact in Xenopus egg extracts and that XXRCC1 immunodepletion resulted in an efficient co-depletion of xLIG3 and vice versa (Figure 2A, Supplementary Figure $\mathrm{S} 2 \mathrm{~B})$.

We then investigated whether xLIG3 contributes to Okazaki fragment joining during S-phase. In the LIG1/XRCC1-depleted extracts, the DNA replication efficiency appeared to be slightly reduced when compared with the mock-depletion, but the reduction was not statistically significant (Supplementary Figure S2C). As mentioned above, the accumulation of Okazaki fragments was observed in xLIG1-depleted extracts, but not in xLIG3xXRCC1-depleted extracts. In contrast, when xLIG1 and xLIG3-xXRCC1 were simultaneously depleted, the amount of nicked Okazaki fragments was markedly increased and was not eliminated over S phase (Figure 2B). We then examined the chromatin binding of xLIG3-xXRCC1 during DNA replication. Both xLIG3 and XXRCC1 were detected on chromatin in mock-depleted extracts. When xLIG1 was depleted, a marked increase in chromatin binding of xLIG3 and $\mathrm{xXRCC1}$ was detected, particularly during late $\mathrm{S}$ phase (Figure 2C, Supplementary Figure S2D). In contrast, xXRCC1 depletion had little effect on the recruitment of xLIG1 to chromatin. Reintroduction of recombinant xLIG3-xXRCC1 complex purified from insect cells to xLIG1/xXRCC1-depleted extracts resulted in a chromatin loading of xLIG3 and xXRCC1 similar to that of endogenous proteins, and rescued impaired Okazaki fragment joining (Figure 2D and E, Supplementary Figure S2F). We also found that the chromatin unloading of PCNA and FEN1 was inhibited in XLIG1/xXRCC1-depleted extracts and the addition of recombinant LIG3-XRCC1 complex to LIG1/XRCC1-depleted extracts efficiently restored the defect, suggesting that the chromatin unloading of PCNA and FEN1 is tightly linked with the completion of Okazaki fragment ligation. Substitution of arginine and lysine in conserved PAR-binding sites of XXRCC1 with alanine (49) (Supplementary Figures S2E and S6B) resulted in only a slight loss of Okazaki fragment joining as compared to wild type-xXRCC1, consistent with that it had no clear effect on XLIG3-xXRCC1 chromatin binding (Figure 2D and E). To directly test the requirement of XRCC1, we analyzed Okazaki fragment ligation during late $\mathrm{S}$ phase in LIG3XRCC1-depleted extracts supplemented with purified recombinant xLIG3-XRCC1-WT complex, xLIG3-WT alone or its derivative mutant lacking the BRCT domain, which is responsible for the binding to XRCC1 (Supplementary Figure S6C) (22). Strikingly, the addition of recombinant xLIG3-WT alone efficiently restored Okazaki fragment ligation in LIG3/XRCC1-depleted extracts, and the deletion of the BRCT domain did not significantly affect the ligation efficiency (Figure 2F). Together, our results suggest that LIG3-XRCC1 is responsible for Okazaki fragment joining when LIG1 function is perturbed, but $\mathrm{XRCC} 1$ is not necessarily required.

\section{HPF1-dependent PARP activation promotes alternative Okazaki fragment ligation}

It has been demonstrated that LIG3-XRCC1 is recruited to single-strand break sites in a PARP1-mediated polyADP-ribosylation dependent manner (25-27). Recent studies also revealed that ADP-ribosylation at serine residues is a major modification upon DNA damage (37-39). ADPribosylation at serine is known to be catalyzed by PARP1 in complex with HPF1, which targets histone proteins and PARP1 per se as a substrate (36-38). We therefore compared the ADP-ribosylation of mock- or xLIG1depleted chromatin using an anti-pan-ADP-ribose binding reagent, which recognizes both mono- and poly-ADPribose. ADP-ribosylation signals were readily detectable in xLIG1-depleted extracts, but not in mock-depleted extracts. Importantly, reintroduction of recombinant wildtype xLIG1, but not its enzymatically inactive mutant, fully suppressed these modifications (Figure 3A, Supplementary Figure S3A). Similar signals were detected when xLIG1 (R794L) and xLIG1 (R924W) mutants were reintroduced in xLIG1-depleted extracts (Supplementary Figure S3B and C). These bands were increased by co-depletion of xPARG with xLIG1, suggesting that they were ADPribosylated proteins (Figure 3B). Depletion of xPARG alone from egg extracts had only a slight effect on ADPribosylation of chromatin. Thus, ADP-ribosylation is likely to be induced by LIG1 dysfunction. Since previous reports showed histone $\mathrm{H} 3$ to be a molecular target of PARP1HPF1-dependent ADP-ribosylation $(36,50)$, we examined whether the $15 \mathrm{kDa}$ band corresponded to histone proteins. Immuoprecipitation of histone $\mathrm{H} 3$ revealed an ADPribosylation signal in anti-H3 immunoprecipitates from xLIG1-depleted, but not mock-depleted chromatin (Figure 3C). In mammalian cells, apart from Okazaki fragment joining, LIG1 is known to be involved in various DNA repair pathways both during and outside of $S$ phase (7). We found that ADP-ribosylation in xLIG1-depleted extracts was completely abolished by the addition of APH (as seen by increased loading of xRPA34) (Figure 3D, Supplementary Figure S3D). The results suggest that histone H3 ADP-ribosylation upon xLIG1-depletion is dependent on DNA replication rather than not the indirect consequence of the accumulation of spontaneous DNA damage or replication fork stalling by xLIG1 depletion. HPF1-dependent ADP-ribosylation is reported to be hydrolyzed by ARH3 (29). Thus, ADP-ribosylation in xLIG1depleted extracts might be sensitive to ARH3. When an excess amount of recombinant wild-type xARH3 purified from bacteria cells, as well as its mutant lacking enzymatic activity (D58N, corresponding to hARH3 D77N) (29) were added to xLIG1-depleted extracts $(0.2-1 \mu \mathrm{M})$, only wild-type recombinant ARH3 diminished histone H3 ADP-ribosylation (Figure 3E, Supplementary Figure S3E). These results suggest that LIG1 deficiency leads to activation of PARP1-HPF1-dependent ADP-ribosylation targeting histone $\mathrm{H} 3$.

To directly test whether ADP-ribosylation is mediated by PARP1 and HPF1, we performed immunodepletion of PARP1 and HPF1 in the absence of LIG1. Under this condition, immunodepletion of XPARP1 partially reduced the 
A

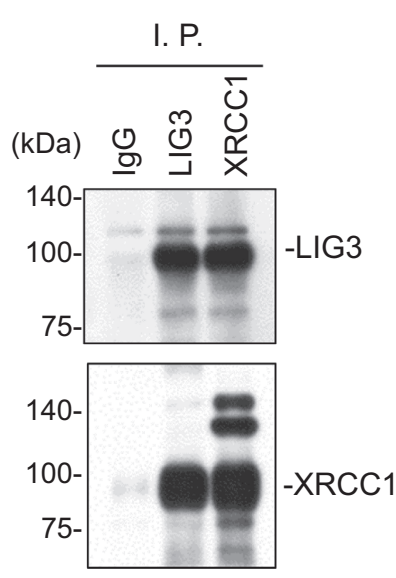

B
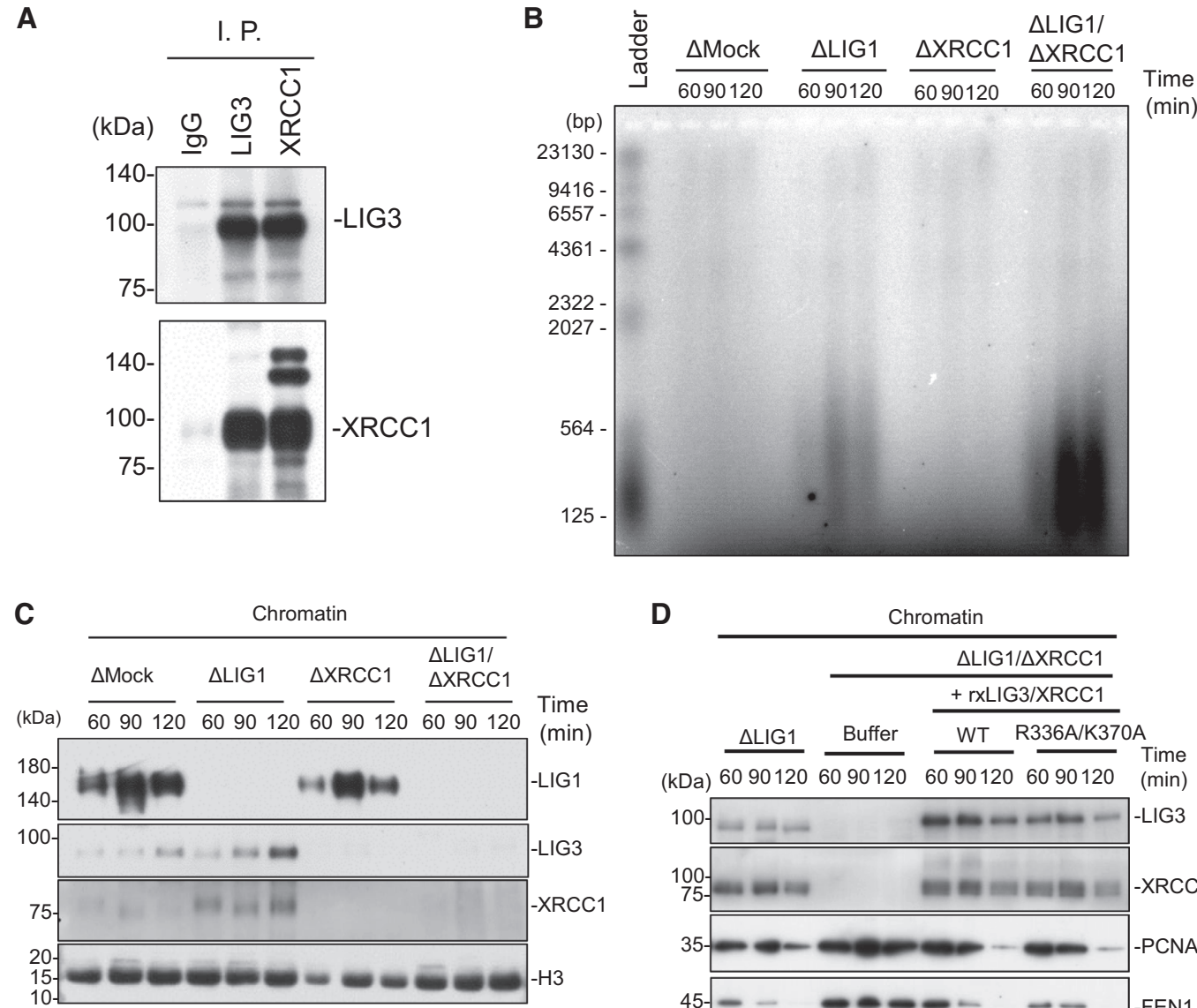

E

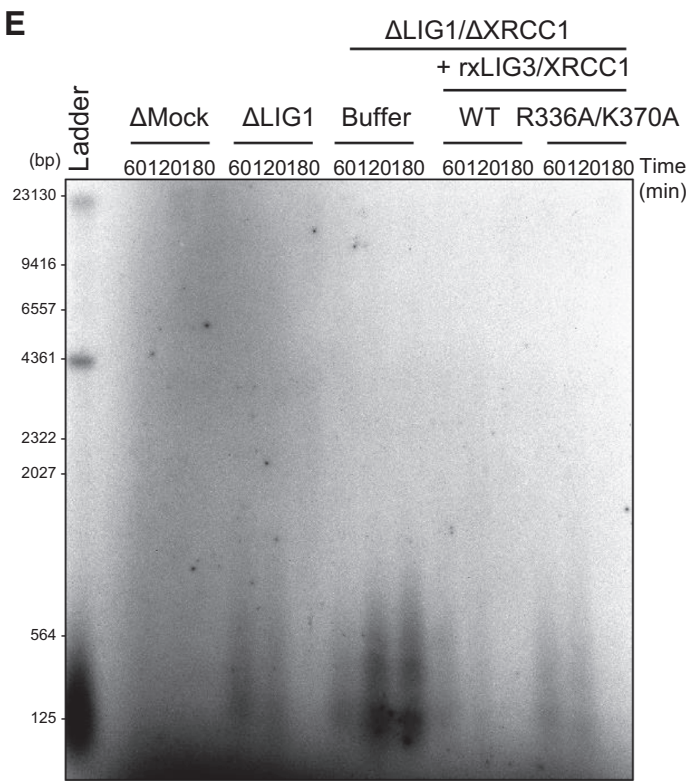

D
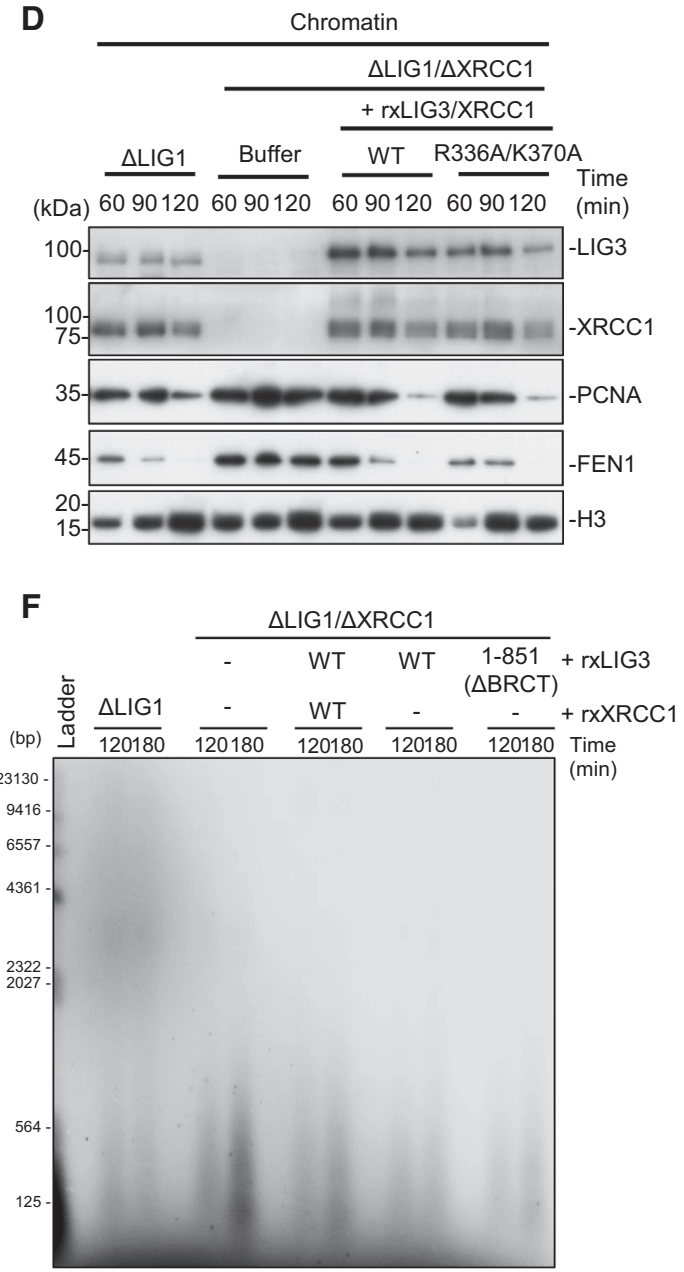

Figure 2. LIG3-XRCC1 ensures Okazaki fragment ligation in the absence of LIG1. (A) Immunoprecipitation (I. P.) of xLIG3 and xXRCC1 from egg extracts. I. P. was performed with anti-xLIG3 or -xXRCC1 antiserum. Pre-immune serum was also used as a control. Immunoprecipitates were analyzed by immunoblotting using the indicated antibodies $(n=2)$. (B) Mock-, xLIG1-, xXRCC1- or xLIG1/xXRCC1-depleted extracts were used to replicate sperm chromatin. Genomic DNA was purified and analyzed as in Figure $1 \mathrm{G}(n=3)$. (C) Chromatin-bound proteins from $(\mathbf{B})$ were monitored by immunoblotting using the indicated antibodies $(\mathrm{n}=3)$. (D) xLIG1- and xLIG1/xXRCC1-depleted extracts were used to replicate sperm chromatin. xLIG1/xXRCC1depleted extracts were supplemented with either buffer (+Buffer), wild-type 3× Flag-xLIG3-xXRCC1-myc, or 3× Flag-xLIG3-xXRCC1-R336AK370Amyc lacking the poly-ADP-ribose binding activity of xXRCC1 $(\mathrm{n}=3)$. (E) Replication products from $(\mathbf{D})$ were analyzed as in Figure 1G $(n=2)$. $(\mathbf{F}) \mathrm{xLIG1-}$ and XLIG1/xXRCC1-depleted extracts were used to replicate sperm chromatin. xLIG1/xXRCC1-depleted extracts were supplemented with either buffer (+Buffer), wild-type $3 \times$ Flag-xLIG3-xXRCC1-myc, $3 \times$ Flag-xLIG3 or $3 \times$ Flag-xLIG3 lacking the BRCT domain. Replication products were analyzed as in Figure 1G $(n=2)$. 
A

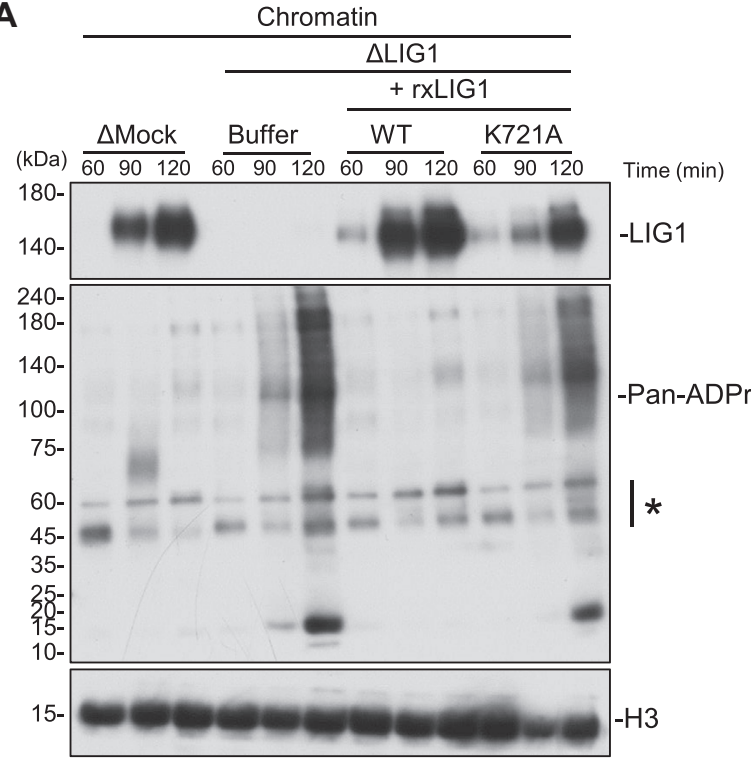

C

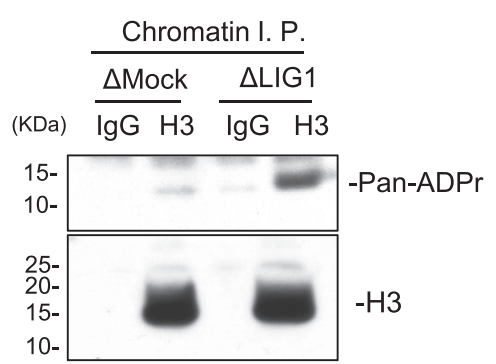

D

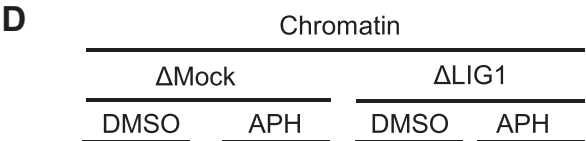

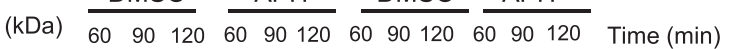

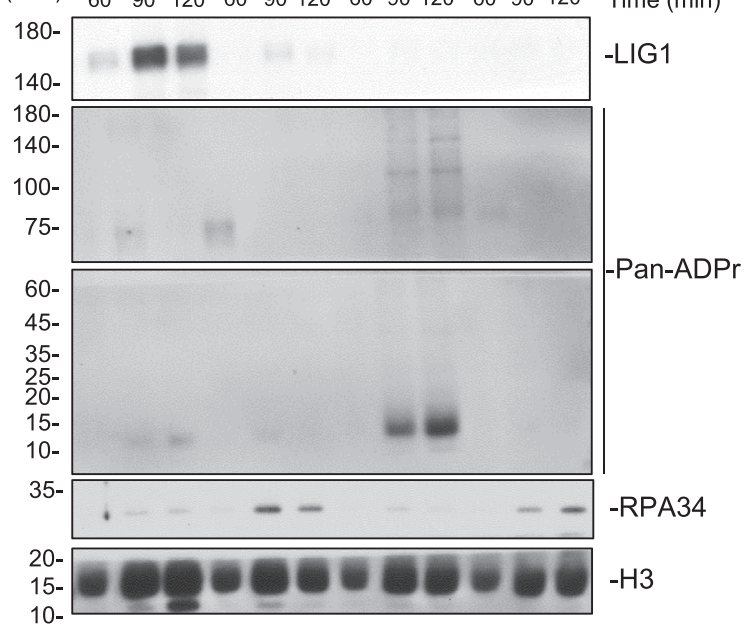

B
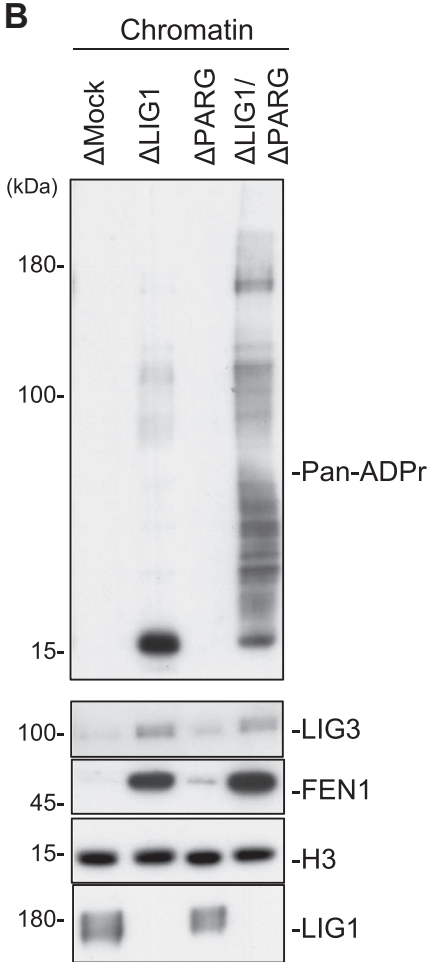

E
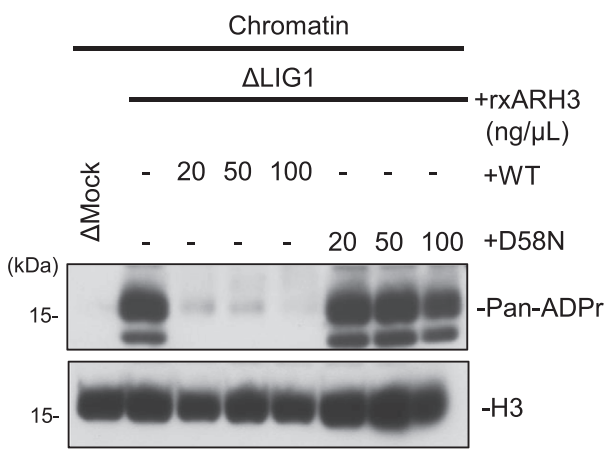

Figure 3. LIG1 deficiency causes histone H3 ADP-ribosylation. (A) Mock- and xLIG1-depleted extracts were used for replication of sperm chromatin. xLIG1-depleted extracts were supplemented with wild-type xLIG1 or xLIG1-K721A. Chromatin-bound proteins were analyzed by immunoblotting using the indicated antibodies and pan ADP-ribose (Pan-ADPr) detecting reagent $(n=3)$. The asterisk indicates a non-specific band. (B) Mock-, xLIG1-, xPARG- and xLIG1/xPARG-depleted extracts were used for replication of sperm nuclei. Chromatin-bound proteins were analyzed as in Figure 3A $(n=2)$. (C) Chromatin fractions from the indicated immunodepleted extracts were solubilized with MNase followed by immunoprecipitation with anti-histone H3 antibodies after treatment with 1\% SDS. The resultant immunoprecipitates were analyzed as in Figure 3A $(n=2)$. (D) Mock- and xLIG1-depleted extracts were used for replication of sperm nuclei in the presence of $30 \mu \mathrm{M}$ APH where indicated. Chromatin-bound proteins were analyzed by immunoblotting using the indicated antibodies and pan ADP-ribose detecting reagent $(n=2)$. (E) Mock- and xLIG1-depleted extracts were used for replication of sperm chromatin. xLIG1-depleted extracts were supplemented with either buffer or recombinant wild-type His10-xARH3 or His10-xARH3-D58N, (0.2-1 $\mu$ M). Chromatin-bound proteins were analyzed by immunoblotting using the indicated antibodies and pan ADP-ribose detecting reagent $(n=2)$. 
level of histone H3 ADP-ribosylation on xLIG1-depleted chromatin (Figure 4A and B). xHPF1 depletion also resulted in a reduction of histone H3 ADP-ribosylation (Figure $4 \mathrm{C}$ and D). These results suggest that PARP2 may compensate for PARP1 depletion in the extracts. However, we cannot exclude the possibility that the residual histone $\mathrm{H} 3$ ADP-ribosylation is due to the incomplete XPARP1 depletion or the activities of other nuclear xPARPs at this stage $(27,51)$. This defect was largely restored by recombinant wild-type xHPF1, but not by a xHPF1 mutant harboring mutations in the conserved acidic corner (alanine substitution of Tyr251 and Arg252, corresponding to hHPF1 Try238 and Arg239), which disrupts the interaction between xHPF1 and xPARP1 (Figure 4E and F) (38). To examine whether the SSBR involves HPF1 and histone H3 ADPribosylation in Xenopus egg extracts, we tested the effect of methyl methanesulfonate (MMS) treatment (36). We found that MMS treatment induced ADP-ribosylation on chromatin, and it was significantly inhibited by HPF1 depletion (Supplementary Figure S4A and B). These results suggest that the PARP1-HPF1 complex stimulates histone H3 ADP-ribosylation in response to single-strand breaks generated in the absence of LIG1.

Based on the above findings, we hypothesized that HPF1dependent ADP-ribosylation promotes LIG3-XRCC1dependent Okazaki fragment ligation. We found that xLIG3 displayed decreased chromatin binding in the absence of XPARP1, which was correlated with a loss of ADPribosylation (Figure 5A, Supplementary Figure S5A). Similarly, the depletion of xHPF1 also inhibited the chromatin binding of xLIG3-xXRCC1 (Figure 5B, Supplementary Figure S5B). The accumulation of xFEN1 and xPCNA on xLIG1-depleted chromatin and gross DNA replication efficiency was not significantly affected by the inhibition of xPARP1/xHPF1. (Figure 5A, B and Supplementary Figure S5C). Consistent with this observation, unligated Okazaki fragments in xLIG1-depleted extracts further increased with xPARP1, or xHPF1 co-depletion (Figure $5 \mathrm{C})$. We then investigated the effects of xLIG1/xPARP1 or xHPF1/xLIG1 depletion on the conversion of Okazaki fragments into high molecular weight DNA. Consistent with results from end labeling experiments, the conversion of labeled short Okazaki fragments into high molecular weight DNA was clearly suppressed in xLIG1/xPARP1or xLIG1/xHPF1-depleted extracts compared to xLIG1depleted extracts (Figure 5D). We also examined whether xLIG3/xXRCC1 interacts with ADP-ribosylated histone $\mathrm{H} 3$ or PCNA. Although we found that xLIG3 and xXRCC1 form a complex on chromatin, $\mathrm{xLIG} 3 / \mathrm{xXRCC} 1$ showed no binding to either ADP-ribosylated histone $\mathrm{H} 3$ or PCNA (Supplementary Figure S5D). Collectively, our data suggest that LIG1 deficiency causes PARP1-HPF1-dependent ADP-ribosylation, which acts to activates LIG3-XRCC1 as a backup pathway for Okazaki fragment ligation (Figure 6).

\section{DISCUSSION}

Co-depletion of LIG1 and LIG4 did not significantly affect cell proliferation (15-17) whereas that of LIG1 and LIG3 induced lethality, suggesting the redundant function of LIG3 in Okazaki fragment ligation. However, the regu- latory mechanisms for how LIG1 and LIG3 function properly during S phase were not clear. Using the Xenopus cellfree replication system, we found that unligated Okazaki fragment accumulates in early to mid-S phase, but is eventually resolved in late $\mathrm{S}$ phase in the absence of LIG1. LIG3-XRCC1 accumulates on chromatin specifically in late $\mathrm{S}$ phase in the LIG1 depleted extracts. Co-depletion of LIG1 and LIG3-XRCC1 resulted in a complete loss of Okazaki fragment joining. Finally, PARP1-HPF1 is essential for LIG3-XRCC1 in Okazaki fragment joining. Consistent with this, LIG1 inhibition was reported to activate PARP at replication sites in mammalian cells (51), although involvement of this PARP activation in LIG3 recruitment has not yet been examined. Previously, XRCC1 was reported to co-localize with PCNA during S phase under unperturbed conditions $(23,24,51)$. Taken together, our results suggest that LIG1 might be frequently perturbed during normal DNA replication, resulting in chromatin sites with impaired Okazaki fragment joining where LIG3-XRCC1 has to be recruited. Supporting this idea, recent genomewide nucleotide resolution mapping of the $3^{\prime}-\mathrm{OH}$ terminus (GLOE-seq) suggested that the complementary actions of LIG1 and LIG3 control the fidelity of Okazaki fragment ligation in human cells (52). Although the precise mechanism of LIG3-XRCC1 chromatin recruitment remains to be determined, our results and those of a previous report (51) suggest that PARP1-HPF1-dependent ADP ribosylation is important for this event. With respect to the activation of PARP1 in LIG1-depleted extracts, PARP1-HPF1 might directly recognize unligated Okazaki fragments through the DNA-binding domain of PARP1 (34), which in turn activate PARP1.

PARP activity is important for the recruitment of LIG3XRCC1 during DNA repair (33), and inhibition of LIG1 and FEN1 activates PARP and promotes PAR synthesis at DNA replication sites $(51,53)$, although the substrate proteins and the mode of ADP ribosylation have not yet been determined. We found that histone $\mathrm{H} 3$ is the main substrate for ADP ribosylation by PARP1-HPF1 in LIG1depleted chromatin. Consistent with this, the immunodepletion of PARP1 or HPF1 attenuated LIG3-XRCC1 function in Okazaki fragment joining. Our findings are in agreement with a recent report that PARP1 and histone $\mathrm{H} 3$ are predominantly mono-ADP-ribosylated upon DNA damage in an HPF1/PARP1-dependent manner (54). Our data suggest that LIG3-mediated ligation of Okazaki fragments does not depend on the PAR binding activity of XRCC1. This is somewhat inconsistent with the finding in human cells that unligated Okazaki fragments promote PAR synthesis at DNA replication sites. According to a previous study, a plausible explanation for the accumulation of PAR at DNA replication sites might lie in the conversion of mono-ADP ribosylation to PAR associated with a reduced PARG activity (51). Under such conditions, the localization of LIG3-XRCC1 may be regulated through the interaction of PARylated histone $\mathrm{H} 3$ or PARP1 with XRCC1, as proposed by Hanzlikova et al. However, this pathway seems to not operate in Xenopus egg extracts in which endogenous PARG efficiently suppresses PAR synthesis. Direct binding of LIG3 to DNA damage has also been reported in EM9 $\mathrm{CHO}$ cells, which do not express XRCC1 (55), and the $\mathrm{ZnF}$ 
A

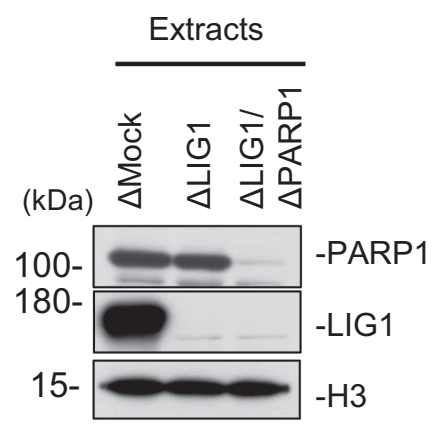

C

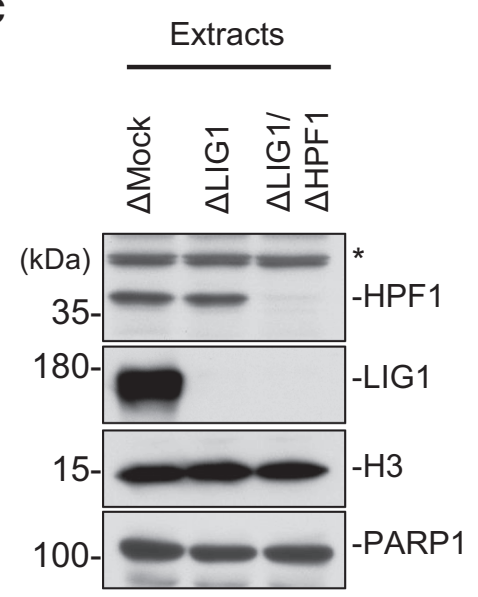

E

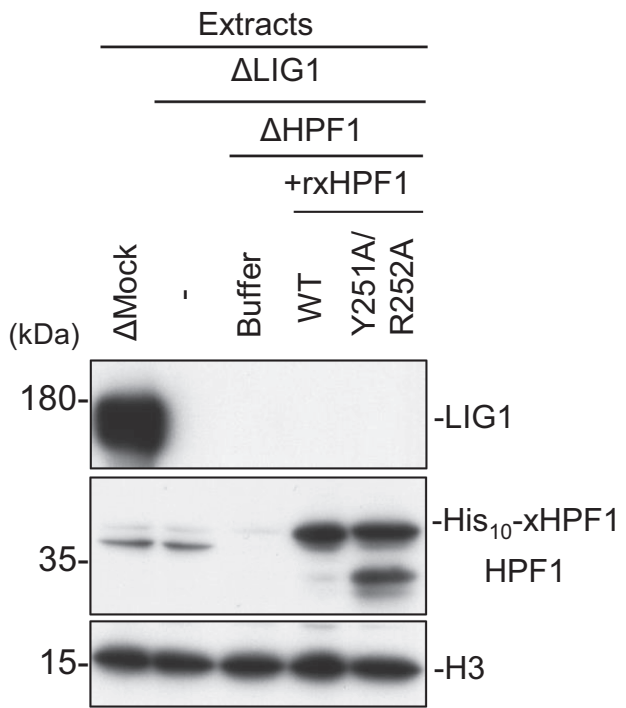

B

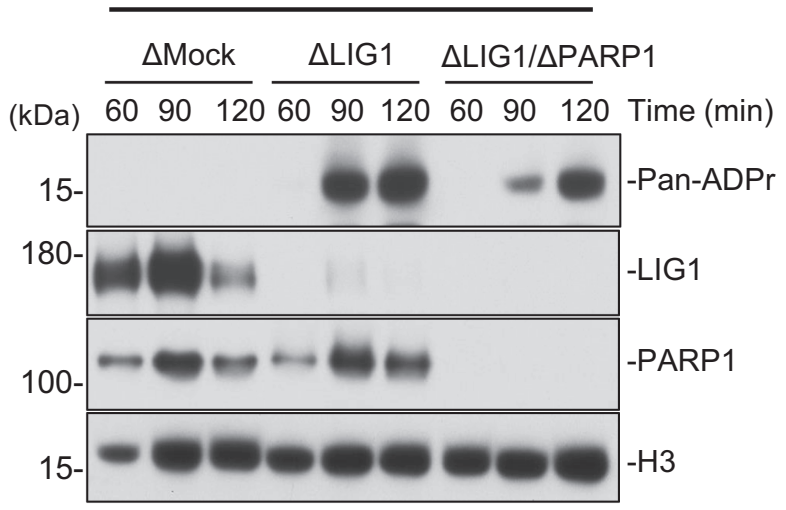

D

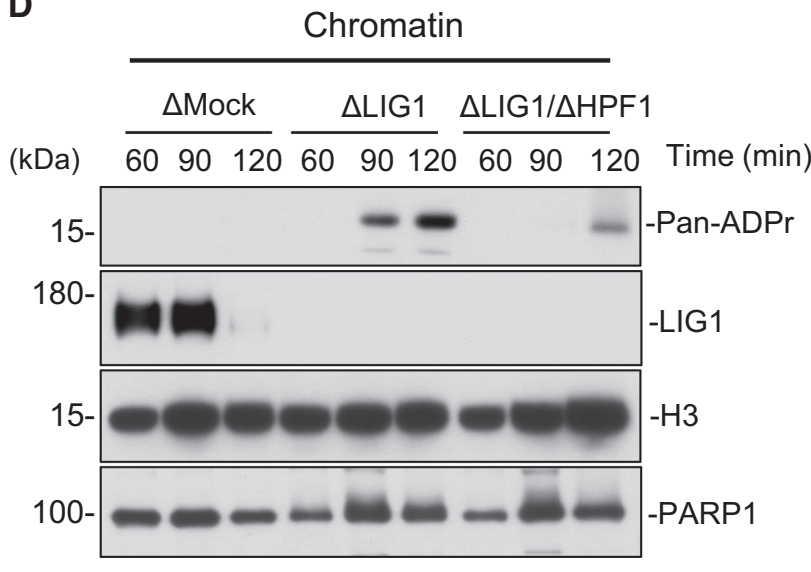

$\mathbf{F}$

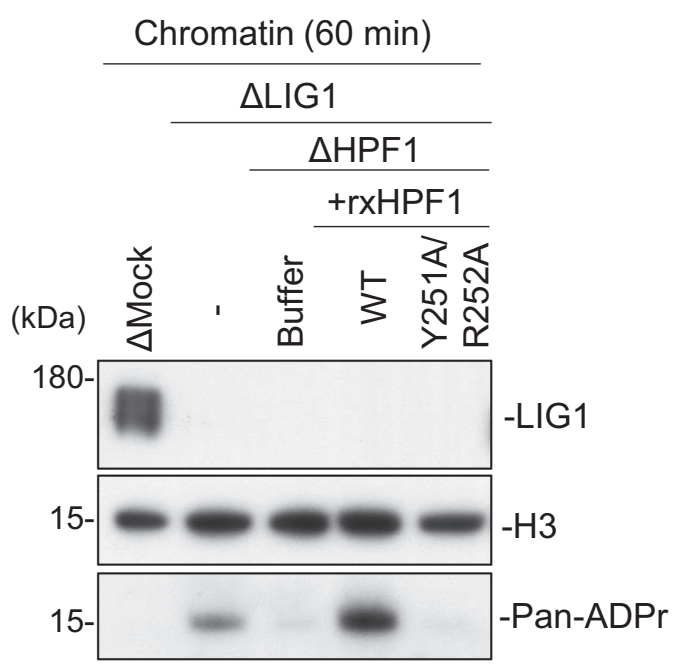

Figure 4. PARP1-HPF1 stimulates histone H3 ADP-ribosylation in LIG1-depleted extracts. (A) Mock-, xLIG1- and xLIG1/xPARP1-depleted extracts were analyzed by immunoblotting using the indicated antibodies. (B) The extracts from (A) were used to replicate sperm nuclei. Chromatin-bound proteins were analyzed by immunoblotting $(n=2)$. (C) Mock-, xLIG1- and xLIG1/xHPF1-depleted extracts were analyzed by immunoblotting using the indicated antibodies. The asterisk indicates a non-specific band. (D) The extracts from $(\mathbf{C})$ were used to replicate sperm nuclei. Chromatin-bound proteins were analyzed $(n=2)$. (E) xLIG1/xHPF1-depleted extracts were supplemented with buffer, recombinant His10-xHPF1 (WT), or recombinant mutant His10xHPF1 (Y251A/R252A) defective for PARP1 binding activity. (F) The extracts from (E) were used to replicate sperm nuclei. Chromatin-bound proteins were analyzed $(n=2)$. 
A

\begin{tabular}{|c|c|c|c|}
\hline \multicolumn{4}{|c|}{ Chromatin } \\
\hline$\Delta$ Mock & $\Delta \mathrm{LIG} 1$ & $\triangle \mathrm{PARP} 1$ & $\begin{array}{l}\Delta \text { LIG1/ } \\
\Delta \text { PARP1 }\end{array}$ \\
\hline
\end{tabular}

(kDa) 6090120609012060901206090120 Time (min)

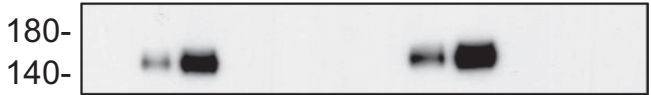

-LIG1

75-

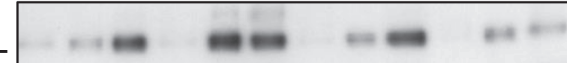

100

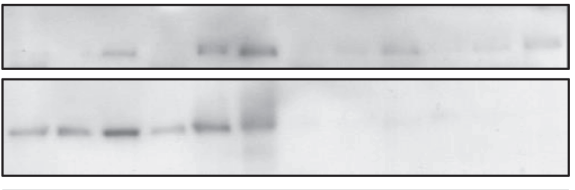

$-X R C C 1$

100

45-

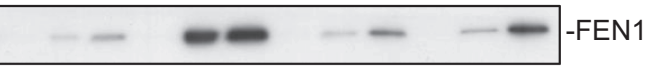

15-
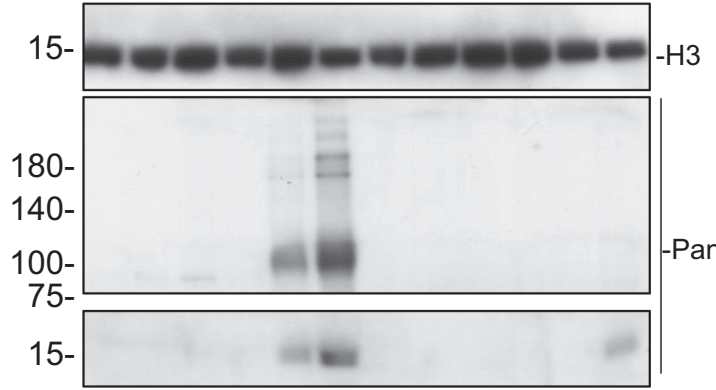

-LIG3

-PARP1

H3

\section{C}

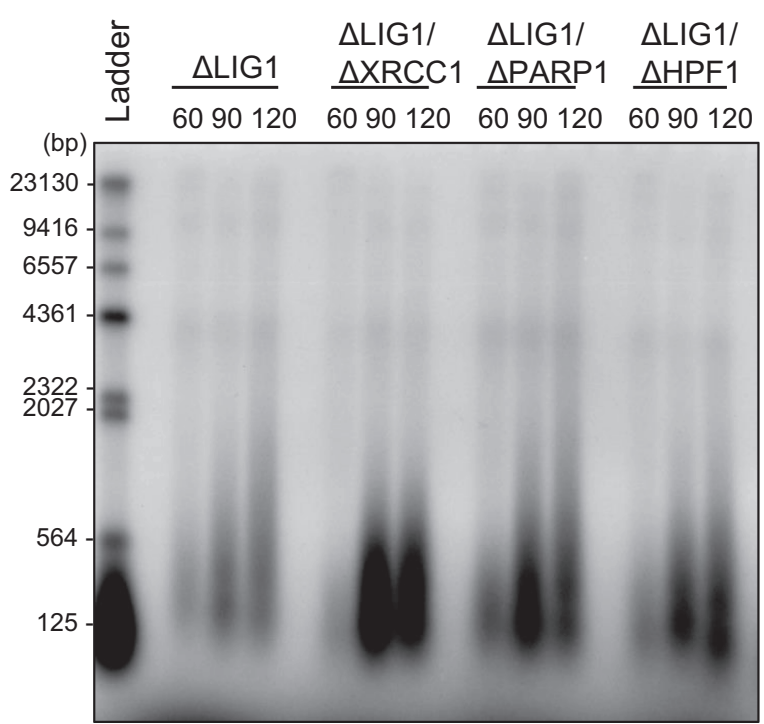

B

Chromatin
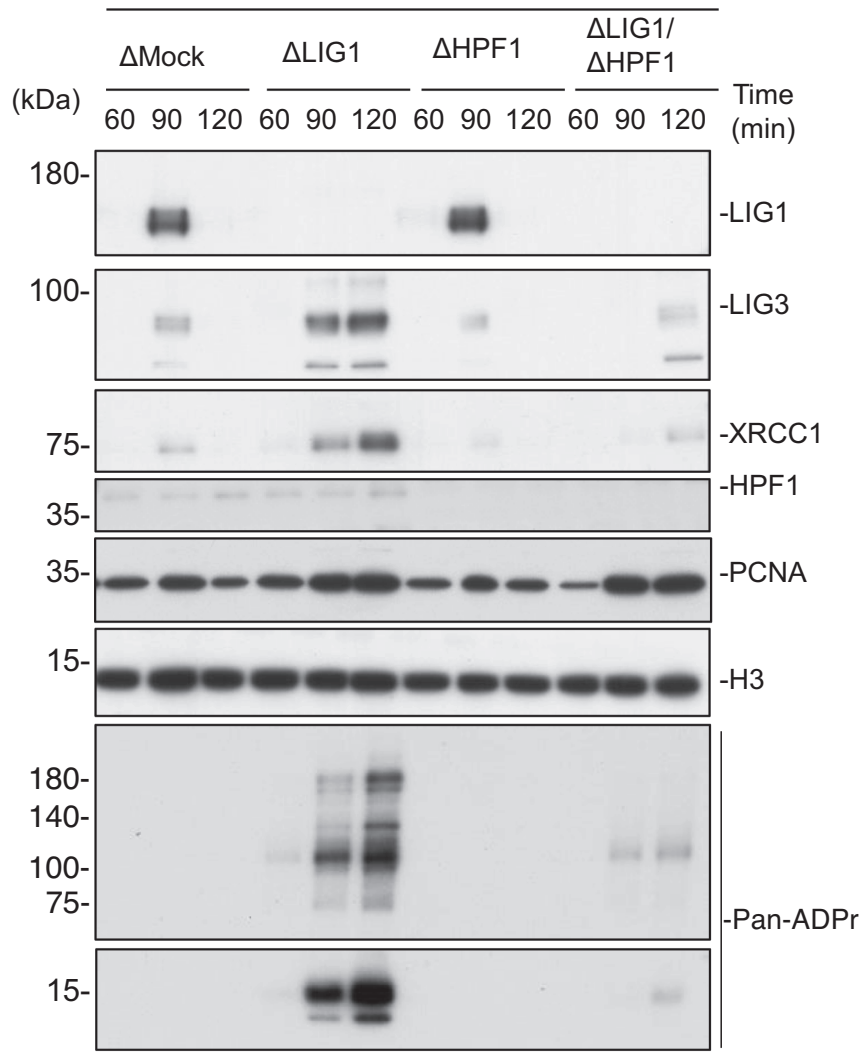

D

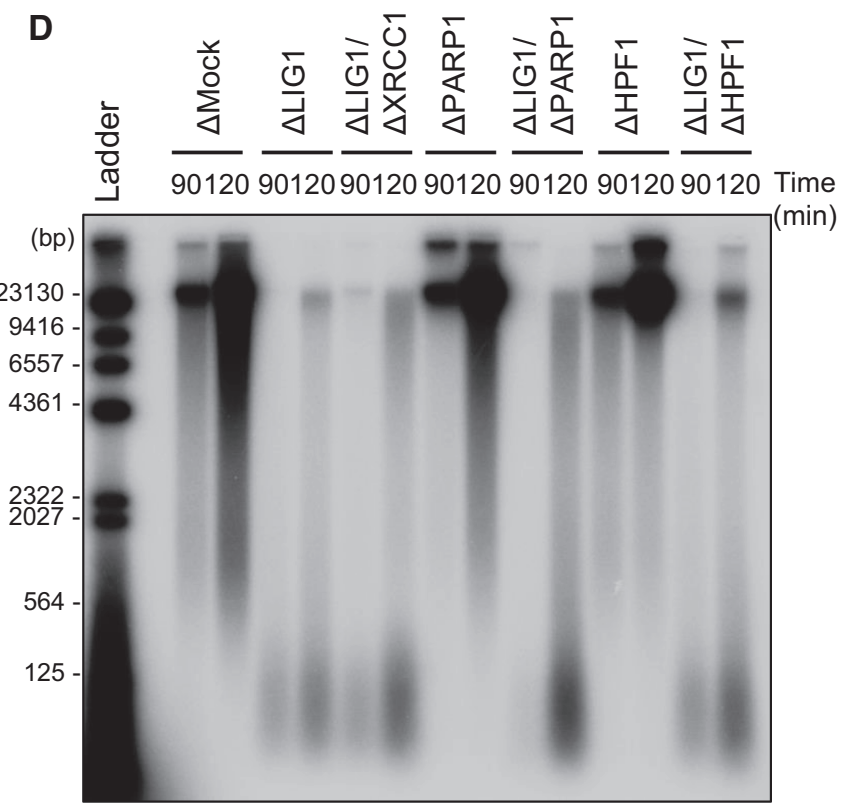

Figure 5. HPF1-dependent PARP activation promotes alternative Okazaki fragment ligation. (A) Mock-, xLIG1-, xPARP1- and xLIG1/xPARP1-depleted extracts were used for replication of sperm nuclei. Chromatin-bound proteins were analyzed by immunoblotting using indicated antibodies $(\mathrm{n}=2)$. $(\mathbf{B})$ Mock-, xLIG1-, xHPF1- and xLIG1/xHPF1-depleted extracts were used for replication of sperm nuclei. Chromatin-bound proteins were analyzed by immunoblotting using the indicated antibodies $(n=2)$. (C) xLIG1-, xLIG1/xXRCC1-, xLIG1/xPARP1- or xLIG1/xHPF1-depleted extracts were used to replicate sperm chromatin. Genomic DNA was purified and labeled using exonuclease-deficient Klenow fragments and $\alpha-{ }^{32} \mathrm{P}$ dCTP. Samples were separated in a denaturing agarose gel, and the incorporation of radioactivity was monitored by autoradiography $(n=3)$. (D) Replication products in mock-, xLIG1-, xLIG1/xXRCC1-, xPARP1-, xLIG1/xPARP1-, xHPF1- or xLIG1/xHPF1-depleted extracts were separated by alkaline agarose gel electrophoresis followed by autoradiography $(n=4)$. 


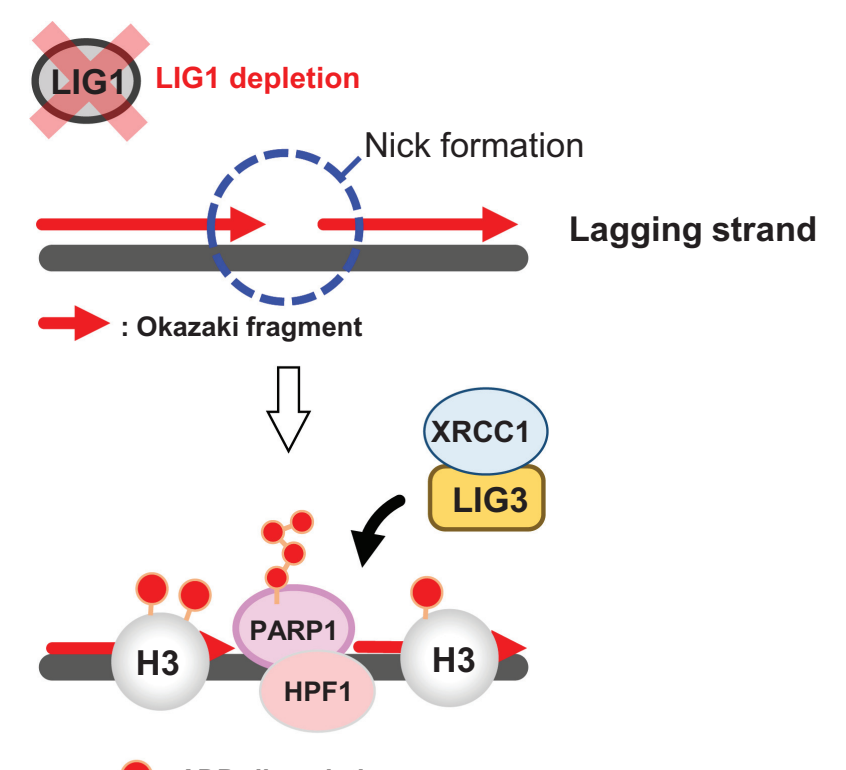

: ADP-ribosylation

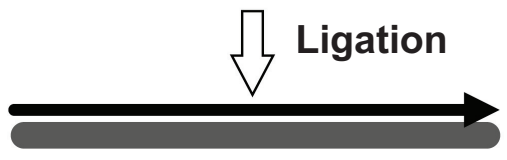

Figure 6. HPF1-dependent PARP activation promotes LIG3-XRCC1mediated backup pathway of Okazaki fragment ligation. In LIG1-depleted egg extracts, the defective Okazaki fragment ligation results in the formation of nicks on the replicating genome. PARP1 binds to DNA at nicks, and ADP-ribosylation of histone $\mathrm{H} 3$ and chromatin-binding proteins is induced in PARP1/HPF1-dependent manner. The LIG3/XRCC1 pathway senses the ADP-ribosylation modification and plays an essential role for the Okazaki fragment joining at the late stage of DNA replication.

domain of LIG3 shows a preference for nicks over gaps (56). Further study is needed to understand how LIG3 localizes to DNA replication sites in an XRCC1-independent manner.

We found that LIG3-XRCC1-mediated Okazaki fragment ligation preferentially occurs in late $\mathrm{S}$ phase. This is consistent with the accumulation of histone H3 ADP ribosylation during middle to late $\mathrm{S}$ phase in LIG1-depleted extracts. A previous study in human cells has also demonstrated that an alternative Okazaki fragment ligation mediated by LIG3 proceeds with significantly slower kinetics than the LIG1-dependent pathway (52). We thus speculate that $\mathrm{S}$ phase progression may also influence HPF1/PARP1 activity. Interestingly, it has been shown that H3K9Ac and $\mathrm{H} 3 \mathrm{~K} 14 \mathrm{Ac}$ interfere with $\mathrm{H} 3$ ADP ribosylation and $\mathrm{H} 3 \mathrm{~K} 9 \mathrm{Ac}$ is mutually exclusive with ADP ribosylation (50). Whether these modifications are involved in Okazaki fragment maturation in the context of DNA replication remains to be determined.

Although our results suggest a possible role of PARP1HPF1-dependent histone H3 ADP-ribosylation in the chromatin recruitment of LIG3-XRCC1, it does not exclude their alternative roles. For example, ADP-ribosylation inhibits the conversion of nicked DNA into double-stranded DNA breaks by preventing DNA2 or EXO1-dependent resection $(57,58)$. ADP-ribosylation is also known to pro- mote ALC1-mediated chromatin remodeling, which may facilitate the access of LIG3/XRCC1 to damaged DNA sites $(36,59,60)$. Intriguingly, PARP1-HPF1 specifically catalyzes ADP ribosylation at a Ser residue. Therefore, LIG3$\mathrm{XRCC1}$ as well as other factors might have unidentified domains which specifically recognize histone H3 ADP ribosylation. Synergistic anti-cancer effects of histone deacetylase (HDAC) and PARP inhibitors are reported in a variety of cancers $(61,62)$. Our current work thus provides an important cue to develop a therapeutic strategy for cancers with FEN1, POL $\delta$ and LIG1 mutations in which Okazaki fragment joining is strongly suppressed upon treatment with PARP and HDAC inhibitors (63).

\section{SUPPLEMENTARY DATA}

Supplementary Data are available at NAR Online.

\section{ACKNOWLEDGEMENTS}

We thank Mitsuko Masutani (Nagasaki University), TehWei Wang (The University of Tokyo) and Alexander S Harris (The University of Tokyo) for critical reading of the manuscript, comments, and discussion.

\section{FUNDING}

MEXT/JSPS KAKENHI [19H05740 to M.N., 19H05285 to A.N.]; A.N. was supported in part by a grant from the Takeda Science Foundation. Funding for open access charge: MEXT [19H05740].

Conflict of interest statement. None declared.

\section{REFERENCES}

1. Moldovan,G.L., Pfander,B. and Jentsch,S. (2007) PCNA, the maestro of the replication fork. Cell, 129, 665-679.

2. Balakrishnan,L. and Bambara,R.A. (2013) Okazaki fragment metabolism. Cold Spring Harb. Perspect. Biol., 5, a010173.

3. Stodola,J.L. and Burgers,P.M. (2017) Mechanism of lagging-strand DNA replication in eukaryotes. Adv. Exp. Med. Biol., 1042, 117-133.

4. Kao,H.I., Campbell,J.L. and Bambara,R.A. (2004) Dna2p helicase/nuclease is a tracking protein, like FEN1, for flap cleavage during okazaki fragment maturation. J. Biol. Chem., 279, 50840-50849.

5. Zheng,L. and Shen,B. (2011) Okazaki fragment maturation: nucleases take centre stage. J. Mol. Cell Biol., 3, 23-30.

6. Kahli,M., Osmundson,J.S., Yeung,R. and Smith,D.J. (2019) Processing of eukaryotic Okazaki fragments by redundant nucleases can be uncoupled from ongoing DNA replication in vivo. Nucleic Acids Res., 47, 1814-1822.

7. Ellenberger,T. and Tomkinson,A.E. (2008) Eukaryotic DNA ligases: structural and functional insights. Annu. Rev. Biochem., 77, 313-338.

8. Liddiard,K., Ruis,B., Kan,Y., Cleal,K., Ashelford,K.E., Hendrickson,E.A. and Baird,D.M. (2019) DNA Ligase 1 is an essential mediator of sister chromatid telomere fusions in $\mathrm{G} 2$ cell cycle phase. Nucleic Acids Res., 47, 2402-2424.

9. Johnston,L.H. and Nasmyth,K.A. (1978) Saccharomyces cerevisiae cell cycle mutant cdc9 is defective in DNA ligase. Nature, 274, 891-893.

10. Johnston,L.H. (1983) The cdc9 ligase joins completed replicons in Baker's yeast. Mol. Gen. Genet., 190, 315-317.

11. Montecucco,A., Rossi,R., Levin,D.S., Gary,R., Park,M.S., Motycka,T.A., Ciarrocchi,G., Villa,A., Biamonti,G. and Tomkinson,A.E. (1998) DNA ligase I is recruited to sites of DNA replication by an interaction with proliferating cell nuclear antigen: identification of a common targeting mechanism for the assembly of replication factories. EMBO J., 17, 3786-3795. 
12. O.jónsson,Z., Hindges,R. and Hübscher,U. (1998) Regulation of DNA replication and repair proteins through interaction with the front side of proliferating cell nuclear antigen. EMBO J., 17, 2412-2425.

13. Vijayakumar,S., Chapados,B.R., Schmidt,K.H., Kolodner,R.D., Tainer,J.A. and Tomkinson,A.E. (2007) The C-terminal domain of yeast PCNA is required for physical and functional interactions with Cdc9 DNA ligase. Nucleic Acids Res., 35, 1624-1637.

14. Levin,D.S., Bai,W., Yao,N., O'Donnell,M. and Tomkinson,A.E. (1997) An interaction between DNA ligase I and proliferating cell nuclear antigen: Implications for Okazaki fragment synthesis and joining. Proc. Natl. Acad. Sci. U.S. A., 94, 12863-12868.

15. Bentley,D.J., Harrison,C., Ketchen,A.M., Redhead,N.J., Samuel,K., Waterfall,M., Ansell,J.D. and Melton,D.W. (2002) DNA ligase I null mouse cells show normal DNA repair activity but altered DNA replication and reduced genome stability. J. Cell Sci. 115, 1551-1561.

16. Arakawa,H., Bednar,T., Wang,M., Paul,K., Mladenov,E., Bencsik-Theilen,A.A. and Iliakis,G. (2012) Functional redundancy between DNA ligases i and III in DNA replication in vertebrate cells. Nucleic Acids Res., 40, 2599-2610.

17. Han,L., Masani,S., Hsieh,C. lin and Yu,K. (2014) DNA ligase I is not essential for mammalian cell viability. Cell Rep., 7, 316-320.

18. Arakawa,H. and Iliakis,G. (2015) Alternative okazaki fragment ligation pathway by dna ligase III. Genes (Basel)., 6, 385-398.

19. Simsek,D. and Jasin,M. (2011) DNA ligase III: A spotty presence in eukaryotes, but an essential function where tested. Cell Cycle, 10, 3636-3644.

20. Caldecott,K.W., McKeown,C.K., Tucker,J.D., Ljungquist,S. and Thompson,L.H. (1994) An interaction between the mammalian DNA repair protein XRCC1 and DNA ligase III. Mol. Cell. Biol., 14, 68-76.

21. Moore,D.J., Taylor,R.M., Clements,P. and Caldecott,K.W. (2000) Mutation of a BRCT domain selectively disrupts DNA single-strand break repair in noncycling Chinese hamster ovary cells. Proc. Natl. Acad. Sci. U.S.A., 97, 13649-13654.

22. Caldecott,K.W. (2019) XRCC1 protein; form and function. DNA Repair (Amst.)., 81, 102664

23. Fan,J., Otterlei,M., Wong,H.K., Tomkinson,A.E. and Wilson,D.M. (2004) XRCC1 co-localizes and physically interacts with PCNA. Nucleic. Acids. Res., 32, 2193-2201.

24. Le Chalony,C., Hoffschir,F., Gauthier,L.R., Gross,J., Biard,D.S., Boussin,F.D. and Pennaneach,V. (2012) Partial complementation of a DNA ligase i deficiency by DNA ligase III and its impact on cell survival and telomere stability in mammalian cells. Cell. Mol. Life Sci., 69, 2933-2949.

25. El-Khamisy,S.F., Masutani,M., Suzuki,H. and Caldecott,K.W. (2003) A requirement for PARP-1 for the assembly or stability of XRCC1 nuclear foci at sites of oxidative DNA damage. Nucleic Acids Res., 31, 5526-5533.

26. Caldecott,K.W. (2008) Single-strand break repair and genetic disease Nat. Rev. Genet. 9, 619-631.

27. Hanzlikova,H., Gittens,W., Krejcikova,K., Zeng,Z. and Caldecott,K.W. (2017) Overlapping roles for PARP1 and PARP2 in the recruitment of endogenous XRCC1 and PNKP into oxidized chromatin. Nucleic Acids Res., 45, 2546-2557.

28. Hottiger,M.O., Hassa,P.O., Lüscher,B., Schüler,H. and Koch-Nolte,F. (2010) Toward a unified nomenclature for mammalian ADP-ribosyltransferases. Trends Biochem. Sci., 35, 208-219.

29. Fontana,P., Bonfiglio,J.J., Palazzo,L., Bartlett,E., Matic,I. and Ahel,I. (2017) Serine ADP-ribosylation reversal by the hydrolase ARH3. Elife, 6, e28533.

30. O’Sullivan,J., Tedim Ferreira,M., Gagné,J.P., Sharma,A.K., Hendzel,M.J., Masson,J.Y. and Poirier,G.G. (2019) Emerging roles of eraser enzymes in the dynamic control of protein ADP-ribosylation. Nat. Commun., 10, 1182.

31. Rack,J.G.M., Palazzo,L. and Ahel,I. (2020) (ADP-ribosyl)hydrolases: structure, function, and biology. Genes Dev., 34, 263-284.

32. Ray Chaudhuri,A. and Nussenzweig,A. (2017) The multifaceted roles of PARP1 in DNA repair and chromatin remodelling. Nat. Rev. Mol. Cell Biol., 18, 610-621.

33. Azarm,K. and Smith,S. (2020) Nuclear PARPs and genome integrity. Genes Dev, 34, 285-301.

34. Ali,A.A.E., Timinszky,G., Arribas-Bosacoma,R., Kozlowski,M., Hassa,P.O., Hassler,M., Ladurner,A.G., Pearl,L.H. and Oliver,A.W.
(2012) The zinc-finger domains of PARP1 cooperate to recognize DNA strand breaks. Nat. Struct. Mol. Biol., 19, 685-692.

35. Satoh,M.S. and Lindahl,T. (1992) Role of poly(ADP-ribose) formation in DNA repair. Nature, 356, 356-358.

36. Gibbs-Seymour,I., Fontana,P., Rack,J.G.M. and Ahel,I. (2016) HPF1/C4orf27 is a PARP-1-interacting protein that regulates PARP-1 ADP-ribosylation activity. Mol. Cell, 62, 432-442.

37. Bonfiglio,J.J., Fontana,P., Zhang,Q., Colby,T., Gibbs-Seymour,I., Atanassov,I., Bartlett,E., Zaja,R., Ahel,I. and Matic,I. (2017) Serine ADP-ribosylation Depends on HPF1. Mol. Cell, 65, 932-940.

38. Suskiewicz,M.J., Zobel,F., Ogden,T.E.H., Fontana,P., Ariza,A., Yang,J.C., Zhu,K., Bracken,L., Hawthorne,W.J., Ahel,D. et al. (2020) HPF 1 completes the PARP active site for DNA damage-induced ADP-ribosylation. Nature, 579, 598-602.

39. Leidecker,O., Bonfiglio,J.J., Colby,T., Zhang,Q., Atanassov,I., Zaja,R., Palazzo,L., Stockum,A., Ahel,I. and Matic,I. (2016) Serine is a new target residue for endogenous ADP-ribosylation on histones. Nat. Chem. Biol., 12, 998-1000.

40. Palazzo,L., Leidecker,O., Prokhorova,E., Dauben,H., Matic,I. and Ahel,I. (2018) Serine is the major residue for ADP-ribosylation upon DNA damage. Elife, 7, e34334

41. Nishiyama,A., Yamaguchi,L., Sharif,J., Johmura,Y., Kawamura,T., Nakanishi,K., Shimamura,S., Arita,K., Kodama,T., Ishikawa,F. et al. (2013) Uhrf1-dependent H3K23 ubiquitylation couples maintenance DNA methylation and replication. Nature, 502, 249-253.

42. Nishiyama,A., Mulholland,C.B., Bultmann,S., Kori,S., Endo,A., Saeki,Y., Qin,W., Trummer,C., Chiba,Y., Yokoyama,H. et al. (2020) Two distinct modes of DNMT1 recruitment ensure stable maintenance DNA methylation. Nat. Commun., 11, 1222.

43. Yamaguchi,L., Nishiyama,A., Misaki,T., Johmura,Y., Ueda,J., Arita,K., Nagao,K., Obuse,C. and Nakanishi,M. (2017) Usp7-dependent histone $\mathrm{H} 3$ deubiquitylation regulates maintenance of DNA methylation. Sci. Rep., 7, 55.

44. Tomkinson,A.E., Totty,N.F., Ginsburg,M. and Lindahl,T. (1991) Location of the active site for enzyme-adenylate formation in DNA ligases. Proc. Natl. Acad. Sci. U.S.A., 88, 400-404.

45. Subramanian,J., Vijayakumar,S., Tomkinson,A.E. and Arnheim,N. (2005) Genetic instability induced by overexpression of DNA ligase I in budding yeast. Genetics, 171, 427-441.

46. Maffucci,P., Chavez,J., Jurkiw,T.J., O’Brien,P.J., Abbott,J.K., Reynolds,P.R., Worth,A., Notarangelo,L.D., Felgentreff,K., Cortes,P. et al. (2018) Biallelic mutations in DNA ligase 1 underlie a spectrum of immune deficiencies. J. Clin. Invest., 128, 5505-5516.

47. Barnes,D.E., Tomkinson,A.E., Lehmann,A.R., Webster,A.D.B. and Lindahl,T. (1992) Mutations in the DNA ligase I gene of an individual with immunodeficiencies and cellular hypersensitivity to DNA-damaging agents. Cell, 69, 495-503.

48. Kubota,T., Katou,Y., Nakato,R., Shirahige,K. and Donaldson,A.D (2015) Replication-coupled PCNA unloading by the Elg1 complex occurs genome-wide and requires Okazaki fragment ligation. Cell Rep., 12, 774-787.

49. Breslin,C., Hornyak,P., Ridley,A., Rulten,S.L., Hanzlikova,H., Oliver,A.W. and Caldecott,K.W. (2015) The XRCC1 phosphate-binding pocket binds poly (ADP-ribose) and is required for XRCC1 function. Nucleic Acids Res., 43, 6934-6944.

50. Bartlett,E., Bonfiglio,J.J., Prokhorova,E., Colby,T., Zobel,F., Ahel,I. and Matic,I. (2018) Interplay of histone marks with serine ADP-ribosylation. Cell Rep., 24, 3488-3502.

51. Hanzlikova,H., Kalasova,I., Demin,A.A., Pennicott,L.E., Cihlarova,Z. and Caldecott,K.W. (2018) The importance of poly(ADP-ribose) polymerase as a sensor of unligated Okazaki fragments during DNA replication. Mol. Cell, 71, 319-331.

52. Sriramachandran,A.M., Petrosino,G., Méndez-Lago,M., Schäfer,A.J., Batista-Nascimento,L.S., Zilio,N. and Ulrich,H.D (2020) Genome-wide nucleotide-resolution mapping of DNA replication patterns, single-strand breaks, and lesions by GLOE-Seq. Mol. Cell, 78, 975-985.

53. Maya-Mendoza,A., Moudry,P., Merchut-Maya,J.M., Lee,M., Strauss, R. and Bartek,J. (2018) High speed of fork progression induces DNA replication stress and genomic instability. Nature, 559, 279-284.

54. Bonfiglio,J.J., Leidecker,O., Dauben,H., Longarini,E.J., Colby,T., San Segundo-Acosta,P., Perez,K.A. and Matic,I. (2020) An 
HPF1/PARP1-based chemical biology strategy for exploring ADP-ribosylation. Cell, 183, 1086-1102.

55. Abdou,I., Poirier,G.G., Hendzel,M.J. and Weinfeld,M. (2015) DNA ligase III acts as a DNA strand break sensor in the cellular orchestration of DNA strand break repair. Nucleic. Acids. Res., 43, $875-892$.

56. Cotner-Gohara,E., Kim,I.K., Tomkinson,A.E. and Ellenberger,T. (2008) Two DNA-binding and nick recognition modules in human DNA ligase III. J. Biol. Chem., 283, 10764-10772.

57. Cheruiyot,A., Paudyal,S.C., Kim,I.K., Sparks,M., Ellenberger,T., Piwnica-Worms,H. and You,Z. (2015) Poly(ADP-ribose)-binding promotes Exol damage recruitment and suppresses its nuclease activities. DNA Repair (Amst.)., 35, 106-115.

58. Thakar,T., Leung,W., Nicolae,C.M., Clements,K.E., Shen,B., Bielinsky,A.K. and Moldovan,G.L. (2020) Ubiquitinated-PCNA protects replication forks from DNA2-mediated degradation by regulating Okazaki fragment maturation and chromatin assembly. Nat. Commun., 11, 2147.

59. Ahel,D., Hořejší,Z., Wiechens,N., Polo,S.E., Garcia-Wilson,E., Ahel,I., Flynn,H., Skehel,M., West,S.C., Jackson,S.P. et al. (2009) Poly(ADP-ribose)-dependent regulation of DNA repair by the chromatin remodeling enzyme ALC1. Science, 325, 1240-1243.
60. Singh,H.R., Nardozza,A.P., Möller,I.R., Knobloch,G., Kistemaker,H.A.V., Hassler,M., Harrer,N., Blessing,C., Eustermann,S., Kotthoff,C. et al. (2017) A Poly-ADP-Ribose trigger releases the auto-inhibition of a chromatin remodeling oncogene. Mol. Cell, 68, 860-871.

61. Ha,K., Fiskus,W., Choi,D.S., Bhaskara,S., Cerchietti,L., Devaraj,S.G.T., Shah,B., Sharma,S., Chang,J.C., Melnick,A.M. et al. (2014) Histone deacetylase inhibitor treatment induces 'BRCAness' and synergistic lethality with PARP inhibitor and cisplatin against human triple negative breast cancer cells. Oncotarget, 5, 5637-5650.

62. Min,A., Im,S.A., Kim,D.K., Song,S.H., Kim,H.J., Lee,K.H., Kim,T.Y., Han,S.W., Oh,D.Y., Kim,T.Y. et al. (2015) Histone deacetylase inhibitor, suberoylanilide hydroxamic acid (SAHA), enhances anti-tumor effects of the poly (ADP-ribose) polymerase (PARP) inhibitor olaparib in triple-negative breast cancer cells. Breast Cancer Res. 17, 33.

63. Chae,Y.K., Anker,J.F., Carneiro,B.A., Chandra,S., Kaplan,J., Kalyan,A., Santa-Maria,C.A., Platanias,L.C. and Giles,F.J. (2016) Genomic landscape of DNA repair genes in cancer. Oncotarget, 7 , 23312-23321. 